\title{
8
}

\section{Assembly of Togaviridae}

\section{Introduction}

The Togaviridae are a family of 4 genera of enveloped RNA viruses with icosahedral nucleocapsids: Alphaviruses, Flaviviruses, Rubiviruses and Pestiviruses (Melnick, 1980). The Alpha- and Flaviviruses are arthropod-borne viruses which can replicate in both vertebrate and arthropod cells. Both Alpha-and Flaviviruses are endemic in bird and animal populations and normally infect humans only as an incidental host (Shope, 1980). In humans, Alphaviruses cause fever, encephalitis, arthritis and rashes as well as inapparent infections. The Flaviviruses also cause fever and encephalitis as well as some hemorrhagic fevers. Rubi- and Pestiviruses are not arthropod-borne and apparently replicate only in vertebrate cells (Shope, 1980). The Rubiviruses are represented by rubella virus, which causes a mild febrile exanthem with teratologic effects in humans. Pestiviruses are responsible for hog cholera, bovine diarrhea and border disease of sheep, important diseases of domestic animals. Among the Togaviridae, the replication and maturation of Alpha-and Flaviviruses have been studied most extensively and will be considered separately in this chapter.

\section{Alphaviruses}

\section{Introduction}

The Alphaviruses are usually mosquito-borne. Each virus is maintained in a single vector species and in a single or several closely related species of vertebrate host, although other animals may be infected incidentally. Infection of the gut of a mosquito by virus-laden blood results in virus replication with minimal cytopathic effects. When virus infection spreads to the salivary glands, the insect becomes 
capable of transmitting the virus. Following infection of a vertebrate by the bite of an infected mosquito, virus replicates in neural and extraneural tissues. Infection may be associated with high levels of viremia and usually elicits protective immunity. Only a small proportion of humans infected with Alphaviruses develops clinically apparent disease.

Six subgroups of Alphaviruses have been defined by serologic studies (Schlesinger, 1980). These subgroups are those which contain Venezuelan equine encephalitis virus (VEE), Eastern equine encephalitis virus (EEE), Western equine encephalitis virus (WEE), Middleburg virus, Ndumu virus, and Semliki Forest virus (SFV). At the molecular biological level, the most extensively studied of the Alphaviruses are Sindbis virus, a member of the WEE subgroup, and Semliki Forest virus.

The virions of Alphaviruses are spherical particles with a diameter of 60-65 nm (Murphy, 1980). The peplomers form an indistinct, fuzzy surface coat around the virion. Detailed studies of purified virions show that the peplomers are $3-3.5 \mathrm{~nm}$ wide, $6-10 \mathrm{~nm}$ long and have a spacing of $4-6 \mathrm{~nm}$ from center to center. The virions have a NC with cubic (icosahedral) symmetry (Horzinek and Mussgay, 1969; Horzinek, 1973 a and b; Enzmann and Weiland, 1979) and the arrangement of peplomers on the virus envelope also appears to show cubic symmetry (Von Bonsdorff and Harrison, 1975; Enzmann and Weiland, 1979; Murphy, 1980).

\section{Molecular Organization}

A comprehensive book (Schlesinger, 1980) and several recent reviews (Kääriäinen and Söderlund, 1978; Garoff et al., 1982; Strauss and Strauss, 1983) provide detailed information on Alphavirus replication. Therefore, the general features of the genomic organization and replicative cycle will be only briefly summarized here. The single stranded $4.4 \times 10^{6} \mathrm{MW}$ genomic RNA is capped and polyadenylated (Kennedy, 1980). Naked virion RNA is infectious, although isolated nucleocapsids are non-infectious.

Adsorption of Alphaviruses to the plasma membrane is followed by endocytosis, uptake of virions into clathrin-coated pits which fuse with lysosomes. Triggered by the low $\mathrm{pH}$ in the endosomes, which may cause a conformational change in the virus glycoproteins (Edwards et al., 1983), the virus envelope fuses with the vesicle membrane to release the virus NC into the cytoplasm (Helenius et al., 1980, 1982; Helenius and Marsh, 1982; Simons et al., 1982).

The transcription and replication of Alphaviruses are summarized in Fig. 8-1 (Kennedy, 1980). Upon entering the cell, virion RNA acts as mRNA to direct the synthesis of a $200 \mathrm{~K}$ to $230 \mathrm{~K}$ dalton precursor to the non-structural proteins. This large precursor is proteolytically cleaved to yield several non-structural proteins which comprise the viral RNA-dependent RNA polymerase complex. The polymerase copies the positive-stranded genomic RNA to make a full length negativestranded template RNA (Sawicki and Sawicki, 1980). The recognition sites for the minus strand replicase may be a highly conserved sequence of 19 nucleotides at the 3 ' end of the genome in concert with a 51 nucleotide sequence located 150 nucleo- 


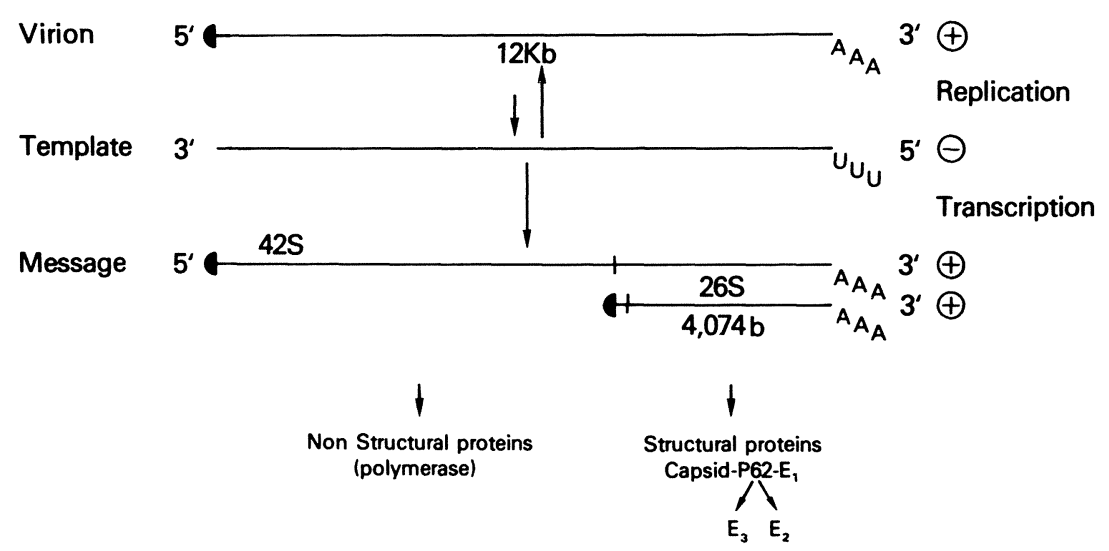

Fig. 8-1. A scheme of the transcription and replication of Alphaviruses. The positive-stranded $12 \mathrm{~Kb}$ genomic RNA in the virion serves as mRNA in the infected cell and directs the synthesis of nonstructural proteins with RNA polymerase activity. This enzyme complex copies the positive-stranded genomic RNA to make a full-length negative-stranded RNA with poly(U) (UUU) at the $5^{\prime}$ end. This is a template for synthesis of new genomic RNA and 26S RNA which serves as a polycistronic mRNA for synthesis of all structural proteins of alphaviruses. Both the genomic RNA and 26S RNA are capped $(-)$ at the $5^{\prime}$ end and polyadenylated (AAA) at the $3^{\prime}$ end. The vertical line on the full length mRNA indicates the end of the non-structural coding region and the beginning of the genes for structural proteins. The vertical line on the $26 \mathrm{~S}$ mRNA indicates the beginning of the open reading frame.

(Adapted from Strauss and Strauss, 1983)

tides from the $5^{\prime}$ end of the genome (Ou et al., 1983; Strauss and Strauss, 1983). Synthesis of the minus strand template is completed by 4 hours after virus inoculation (Sawicki and Sawicki, 1980). Synthesis of positive-stranded 42S genomic RNA and $26 \mathrm{~S}$ mRNA then occurs. The 42S RNA is transcribed by a positive-strand replicase while the 26S mRNA is transcribed by the transcriptase (Gomatos et al.,1980). The transcriptase may initiate mRNA synthesis at a highly conserved 21 nucleotide sequence near the beginning of the $26 \mathrm{~S}$ coding region on the negative-stranded template (Strauss and Strauss, 1983). The 26S mRNA is polycistronic and directs the synthesis of a polyprotein which is cleaved to yield all of the structural proteins. Although the nucleus is not required for replication of Alphaviruses in vertebrate cells, in cells of Aedes albopictus, replication of Sindbis virus is reported to require the host cell nucleus (Erwin and Brown, 1983).

\section{Virus Proteins}

The proteins of the Alphaviruses have been studied in great detail as models for the translation, membrane translocation, intracellular transport and processing of cellular proteins as well as to elucidate important processes in Alphavirus assembly (Bonatti et al., 1979; Simons et al., 1980; Kondor-Koch et al., 1982). Important properties of the non-structural and structural proteins are summarized in Table 8-1. The virion is formed of equimolar ratios of each of the structural proteins.

(1) The capsid protein, $C(\mathrm{MW}: 30 \mathrm{~K})$ interacts with the virus genomic RNA and also with the carboxyl-terminal domains of the $E_{2}$ glycoprotein. $C$ also appears to 
Table 8-1. Proteins of Alphaviruses

\begin{tabular}{|c|c|c|c|c|}
\hline $\begin{array}{l}\text { Usual } \\
\text { name }\end{array}$ & $\begin{array}{l}\text { Apparent MW } \\
\mathrm{X} 10^{-3}\end{array}$ & $\begin{array}{l}\text { Number of } \\
\text { amino acids }\end{array}$ & $\begin{array}{l}\text { Copies } \\
\text { per virion }\end{array}$ & $\begin{array}{l}\text { Known or putative } \\
\text { function }\end{array}$ \\
\hline C & 30 & 267 & 250 & $\begin{array}{l}\text { NC protein } \\
\text { Protease activity? }\end{array}$ \\
\hline E1 & $49-59$ & 438 & 250 & $\begin{array}{l}\text { Surface glycoprotein } \\
\text { Hemagglutinin } \\
\text { Membrane fusion? }\end{array}$ \\
\hline $\mathrm{E} 2$ & $47-52$ & 422 & 250 & $\begin{array}{l}\text { Surface glycoprotein } \\
\text { Interaction with core }\end{array}$ \\
\hline E3 & 10 & 63 & 250 & $\begin{array}{l}\text { Surface glycoprotein } \\
\text { Signal peptide for p } 62\end{array}$ \\
\hline $6 \mathrm{~K}$ & $4.2-6$ & $55-60$ & - & Signal peptide for $E_{1}$ \\
\hline NS70 & 70 & & - & $\begin{array}{l}\text { Replicase/transcriptase } \\
\text { complex (protease?) }\end{array}$ \\
\hline NS86 & 86 & & - & $\begin{array}{l}\text { Replicase/transcriptase } \\
\text { complex (protease?) }\end{array}$ \\
\hline NS72 & 72 & & - & $\begin{array}{l}\text { Replicase/transcriptase } \\
\text { complex (protease?) }\end{array}$ \\
\hline NS60 & 60 & & - & $\begin{array}{l}\text { Replicase/transcriptase } \\
\text { complex (protease?) }\end{array}$ \\
\hline
\end{tabular}

have protease activity which cleaves $C$ protein from the large protein precursor. Complete amino acid sequences of $\mathrm{C}$ proteins from several Alphaviruses have been deduced from nucleotide sequences (Boege et al., 1980; Garoff et al., 1980 a; Rice and Strauss, 1981).

(2) $E 1$ (MW: 49-59 K) is a transmembrane envelope glycoprotein component of the virus peplomer or spike. The carboxyl end is anchored in the lipid bilayer (Garoff and Soderlund, 1978). E1 has hemagglutinating activity and appears to be responsible for virus-induced cell fusion. It induces cross-reactive, non-neutralizing antibodies (Dalrymple et al., 1976). The amino acid sequences of several Alphavirus glycoproteins have been determined (Garoff et al., 1980 b; Rice and Strauss, 1981).

(3) E2 (MW: $47-52 \mathrm{~K}$ ) is a transmembranous glycoprotein which induces typespecific neutralizing antibody (Dalrymple et al.,1976). E2 interacts with E1 and E3 to form the viral peplomers. The carboxyl-terminal domain of $\mathrm{E} 2$ interacts with the $\mathrm{C}$ protein of the viral NC.

(4) $E 3(\mathrm{MW}: 10 \mathrm{~K})$ is a peripheral glycoprotein associated with the spikes of SFV. E3 is released from Sindbis virions (Welch and Sefton, 1979) and WEE (Simizu et al,, 1983) and does not appear to have an essential function in the virion. However, during synthesis of the viral envelope glycoproteins, the E3 region of p62, the precursor for E3 and E2, contains the signal sequence for $\mathrm{p} 62$ (Mayne et al., in press).

(5) Several non-structural proteins are found in cells infected with Alphaviruses. They are produced by proteolytic cleavage of the polyprotein encoded in the $5^{\prime}$ region of the 42S RNA and they appear to be involved in virus RNA dependent RNA polymerase activity. 


\section{Protein Synthesis, Transport and Post-Translational Modifications}

The synthesis and transport of the virus structural proteins are somewhat different in the cells of vertebrates and invertebrates. Infection of invertebrate cells results in intracellular budding of virions and is more likely to lead to persistent infection, whereas infection of cells from vertebrates results in budding of virions from the plasma membrane and leads to cell death (Stollar, $1980 \mathrm{~b}$; Lehane and Leake, 1982). This chapter will focus on Alphavirus replication in cells from vertebrates, and compare specific differences observed in invertebrate cells.

The $26 \mathrm{~S}$ mRNA which directs the synthesis of the viral structural proteins is made in great excess over the $42 \mathrm{~S}$ genomic RNA. Translation of the $26 \mathrm{~S}$ mRNA has been studied extensively in cell-free translation systems, in microinjection studies, in pulse-labeling experiments, and in cell fractionation studies (Clegg, 1975; Bonatti et al., 1979; Schlesinger and Kääriäinen, 1980; Kondor-Koch et al., 1982). Translation of the 26S RNA begins on free ribosomes with the synthesis of the capsid protein. The nascent capsid protein is cleaved from the growing polypeptide chain, apparently by proteolytic activity of the capsid protein itself. This reveals a signal sequence at the amino terminus near the cleavage site. This signal sequence allows the ribosome-26S RNA complex to attach to the RER via signal recognition particles. Following insertion of the signal sequence into the RER membrane, a large glycoprotein is synthesized on membrane-bound ribosomes and translocated across the RER membrane. During its synthesis, this precursor is cleaved in two places, releasing a $6 \mathrm{k}$ protein and yielding the $\mathrm{p} 62$ and $\mathrm{E} 1$ glycoproteins. Mannoserich core oligosaccharides are added cotranslationally to asparagine residues on p62 and $\mathrm{E} 1$ in the RER.

The glycoproteins are then transported to the Golgi apparatus where fatty acids are added (Schmidt and Schlesinger, 1980) in the cis or medial cisternae (Griffiths et al., 1983). Trimming of the high-mannose oligosaccharides and addition of terminal sugars occur in the trans cisternae (Pesonen et al., 1981; Griffiths et al., 1982; Pesonen and Kääriäinen, 1982). A final step in the maturation of the virus glycoproteins occurs in the Golgi or at the plasma membrane where p62 is cleaved to yieldE2 and E3 (Brown, 1980; Ziemiecki et al., 1980; Mayne et al., in press). Details of virus glycoprotein processing differ in arthropod cells, in that the virus glycoproteins obtain different oligosaccharides using host cell glycosyl transferases and trimming enzymes (Stollar, 1980 b).

Fluorescent antibody labeling, immunoelectron microscopy and cell fractionation experiments have been used to study the intracellular transport of Alphavirus glycoproteins (Erwin and Brown, 1980; Scheefers et al., 1980; Saraste et al., 1980 a, b; Green et al., 1981 a; Griffiths et al., 1982, 1983; Arias et al., 1983; Fig. 8-2). Using goldor ferritin-labeled antibody directed against the glycoproteins in cells treated with cycloheximide to inhibit further virus protein synthesis, these studies have shown that these molecules pass from the RER through the Golgi and then to the plasma membrane (Green et al., 1981 a; Griffiths et al., 1983). On the plasma membrane of cells from vertebrates, the virus glycoproteins are found in patches over areas where NC has bound to the cytoplasmic side of the membrane, as well as in budding 


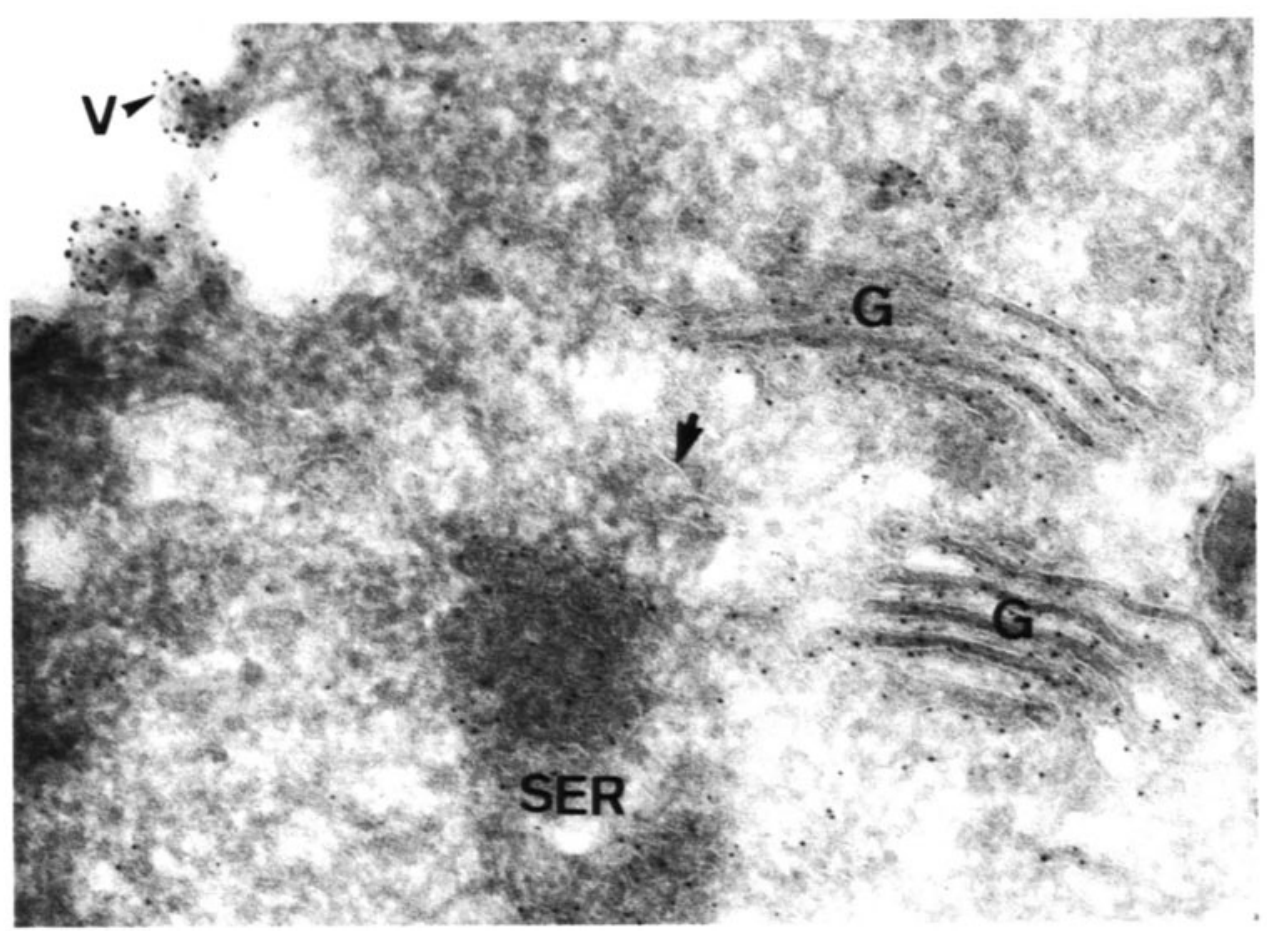

Fig. 8-2. Localization of virus spike glycoproteins of Semliki Forest virus (SFV) in the smooth endoplasmic reticulum (SER) and Golgi apparatus. A frozen thin section of an SFV-infected cell was immunolabeled with an affinity-purified antibody against the virus spike proteins followed by Staphylococcus aureus protein A-gold complex. Extensive labeling is seen over Golgi stacks $(G)$ as well as over SER. The labeling of the rough ER (arrow) is always considerably less than that of the SER. Labeled budding virions $(V)$ are seen at the plasma membrane. Magnification: $\times 80,000$. (Courtesy of Dr. G. Warren from Griffiths et al., 1983, with permission from the Rockefeller University Press)

virions (Griffiths et al., 1983; Fig. 8-2). In contrast, in cells from invertebrates, relatively little virus glycoprotein appears on the plasma membrane (Lehane and Leake, 1982).

Apparently, p62 and E1 form a complex immediately after synthesis (Ziemiecki et al., 1980). Complexes of $\mathrm{p} 62$ and E1 can be isolated from the RER and these proteins can be chemically cross-linked to RER membranes. However, as will be shown below, mixed infection with different Alphaviruses or mutants of Alphaviruses can result in formation of pseudotype virions which contain E2 and E1 from different parental viruses. This suggests either that there is reassortment between E1 and $\mathrm{E} 2$ on the membranes, or that intact spikes from different viruses may be mixed in one virus envelope. Fluorescence photobleaching recovery experiments suggest that the Alphavirus glycoproteins are initially mobile in the plasma membrane, but become increasingly immobilized as virus budding proceeds (Johnson et al., 1982). Complexes of E1, E2, and E3 are quite stable. They can be solubilized from virions (Helenius and von Bonsdorff, 1976; Ziemiecki and Garoff, 1978), formed into micelles (Morein et al., 1978; Simons et al., 1978), reinserted into membranes (Helenius et al., 1981) and associated in vitro with NCs (Helenius and Kartenbeck, 1980). 


\section{Assembly of Virus Components}

Morphogenesis of Alphaviruses has been studied extensively and is the subject of many detailed reviews (Kääriäinen and Söderlund, 1978; Garoff, 1979; Brown, 1980; Murphy, 1980; Simons and Garoff, 1980; Garoff et al., 1982; Simons et al., 1982). Elucidation of the molecular interactions associated with Alphavirus budding has provided important information about cellular processes required for maturation of enveloped viruses.

\section{NC Assembly}

Newly synthesized C protein quickly and efficiently assembles with the $42 \mathrm{~S}$ genomic RNA in the cytoplasm to form NCs (Söderlund, 1973). This interaction is believed to occur between a cluster of basic amino acids and proline near the amino terminus of the $\mathrm{C}$ protein and a region near the $5^{\prime}$ end of the 42S RNA (Rice and Strauss, 1981). No free C protein can be isolated from Alphavirus-infected cells. A transient $90 \mathrm{~S}$ precursor of Semliki Forest virus NC isolated from infected cells contains 42S RNA with a small amount of capsid protein, but it is difficult to detect after capsid protein is being made in large amounts (Ulmanen, 1978).

NCs of Alphaviruses have been purified following disruption of the virus envelope by enzymes or detergents. In negatively stained preparations, the NCs appear spherical and rather deformable and have diameters of 35-39 $\mathrm{nm}$ (Horzinek and Mussgay, 1969; Murphy, 1980). Fixation with formaldehyde yields NCs with symmetrically arranged subunits in an icosahedral lattice with a 3-fold axis of symmetry. At acid $\mathrm{pH}$, the NC of SFV undergoes an irreversible contraction (Söderlund et al., 1971). This may occur in the acid environment of the endocytic vesicles following virus uptake, and might facilitate separation of the NC from the virus envelope which fuses with the vesicular membrane.

In vitro assembly of NCs has been achieved (Wengler et al., 1982). Purified C protein of Sindbis can react with isolated viral genomic RNA, with other single-stranded RNAs or even with single-stranded DNA of a variety of sizes to form core-like NCs with the size, density, and sedimentation velocity of the NCs isolated from virions by detergent disruption. These observations suggest that $\mathrm{C}$ is a nucleic acidbinding protein which can self-aggregate to form a capsid with cubic symmetry only when it is bound to nucleic acid. This would explain why no empty capsids are formed during Alphavirus replication. In the cell, assembly of NCs is very specific and only the $42 S$ genomic RNA or deletions of the $42 S$ RNA which yield defective interfering virions are encapsidated (Stollar, $1980 \mathrm{a}$ ).

The formation of an icosahedral NC from 42S RNA and C protein depends upon electrostatic interactions between RNA and basic amino acids, and upon protein-protein interactions which have not yet been defined. In the icosahedral capsid, $\mathrm{C}$ protein is probably oriented with the amino-terminal end toward the interior and the carboxyl-terminal end on the outside of the capsid where it can interact with virus glycoproteins (Rice and Strauss, 1981; Strauss and Strauss, 1983).

It is not clear how the NCs of Alphaviruses move to the membrane which is the virus budding site. Is the NC assembled in situ on the membrane or does the newly 
formed NC containing the genomic RNA and C protein quickly migrate to the membrane after assembly?

\section{Interactions Between NC and Envelope Proteins}

In cells from vertebrates, Alphaviruses mature by budding from the plasma membrane (Figs. 8-2 to 8-5). NCs associate with regions of the plasma membrane which contain virus glycoproteins (Fig. 8-2). This association appears to occur via the cytoplasmic carboxyl-terminal domain of the p62 glycoprotein. Binding of the $\mathrm{NC}$ to the membrane appears to require a critical concentration of this glycoprotein on the membrane, since mutants which fail to transport the glycoproteins to the plasma membrane do not bind NCs to the plasma membrane (Erwin and Brown, 1980).

Detailed models for Alphavirus budding have been proposed (Simons and Garoff, 1980; Brown, 1980; Garoff et al., 1982; Strauss and Strauss, in press). Following the first interaction of the $\mathrm{NC}$ with the cytoplasmic domain of $\mathrm{p} 62$, the precursor is proteolytically cleaved to yield E2 and E3. This results in a conformational change of E2 (Edwards et al., 1982) and may strengthen the association of E2 with E1. Additional dimers of E1 and p62 glycoproteins which randomly move in the plane of the membrane into this region are then co-operatively bound to the $\mathrm{NC}$-glycoprotein complex. This process forms the budding virion and results in the exclusion of cellular membrane proteins from the virus envelope. Because the virion contains an equimolar ratio of all of the virus structural proteins, it appears likely that one spike may bind to each $\mathrm{C}$ protein of the NC. Indeed, the lipid bilayer may merely provide a matrix for forming a planar array of glycoproteins, and lipid per se may not participate in the interaction of the NC with the glycoproteins. For example, in vitro, all virus lipids can be removed from virions with the detergent octyl glucoside and the virus glycoproteins remain attached to the NC. Also, the spikes can be dissociated and reassociated with the NC in the absence of lipid (Helenius and von Bonsdorff, 1976; Helenius and Kartenbeck, 1980).

Negative staining and freeze etching studies have clearly demonstrated that, unlike most of the other enveloped RNA viruses, the envelope of Alphaviruses exhibits icosahedral symmetry $(\mathrm{T}=4)$ (von Bonsdorff and Harrison, 1975). This may be due to the strong transmembrane interactions between the peplomers and the virus nucleocapsid.

Why do Alphaviruses normally bud from the plasma membrane rather than from intracytoplasmic membranes? Probably NCs can bind to any membrane where sufficient virus glycoproteins are present. During the period of exponential virus release, the virus glycoproteins are on the plasma membrane, so binding of NCs occurs there. However, when large amounts of virus glycoproteins are present in intracytoplasmic membranes, such as late in the infectious cycle or in cells infected with virus mutants defective in glycoprotein transport, binding of NCs may occur at these intracellular membranes. Budding of Alphaviruses into intracytoplasmic membranes has been observed under these conditions (Saraste et al., $1980 \mathrm{a}$ and b). Brown (1980) has suggested that budding from internal membranes might 

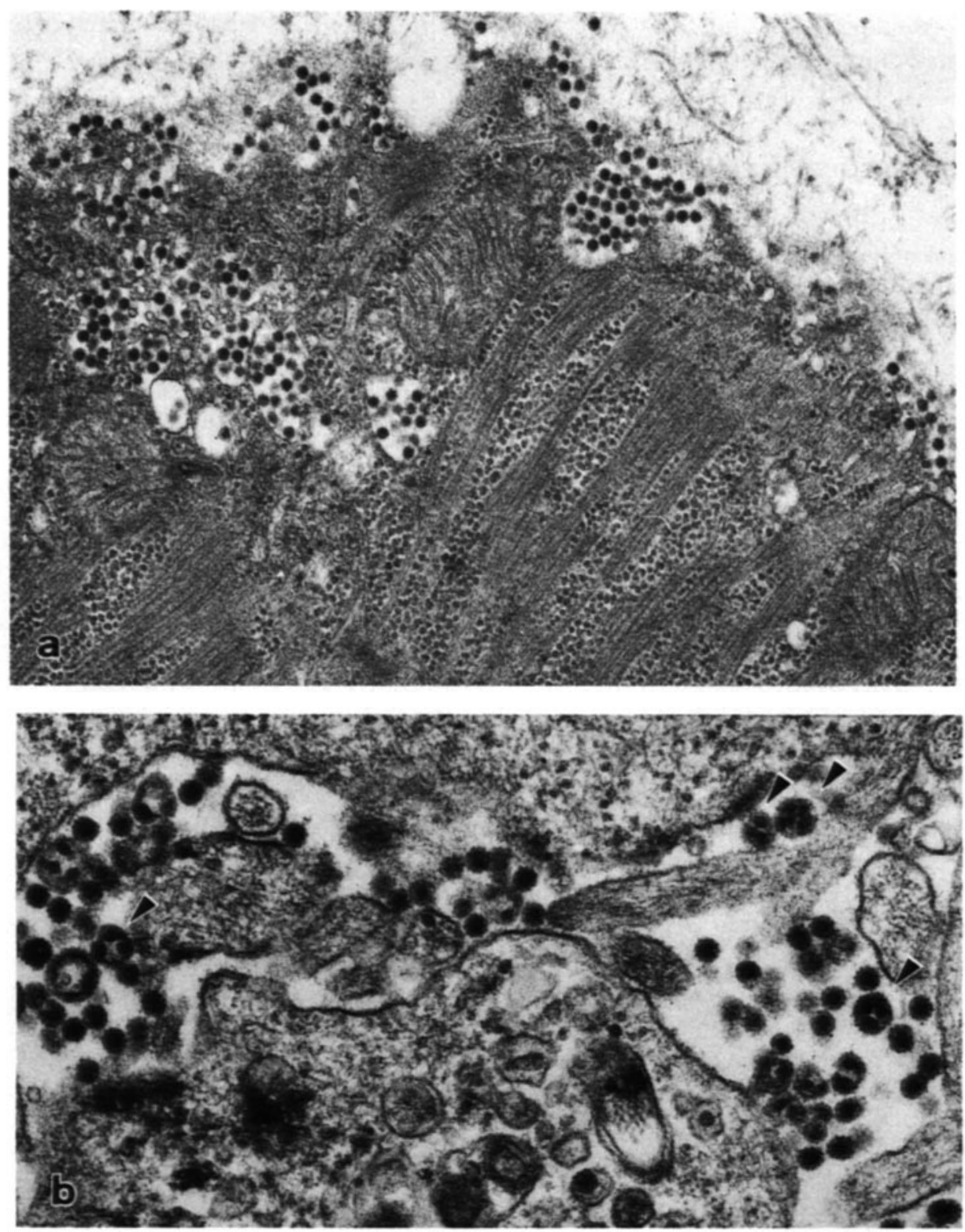

Fig. 8-3. Alphaviruses at the plasma membrane of infected cells. In panel (a), SFV virions released from a striated muscle cell are trapped near the cell membrane. (b) shows normal Western equine encephalitis virus (WEE) virions and virions containing multiple NCs (arrowheads). Such multiploid virions occur occasionally in normal infections but are very common in cells infected with certain virus mutants. Magnifications: (a) $\times 32,800$; (b) $\times 47,500$. (Figs. 8-3 to 8-5 courtesy of Dr. P. Grimley) 


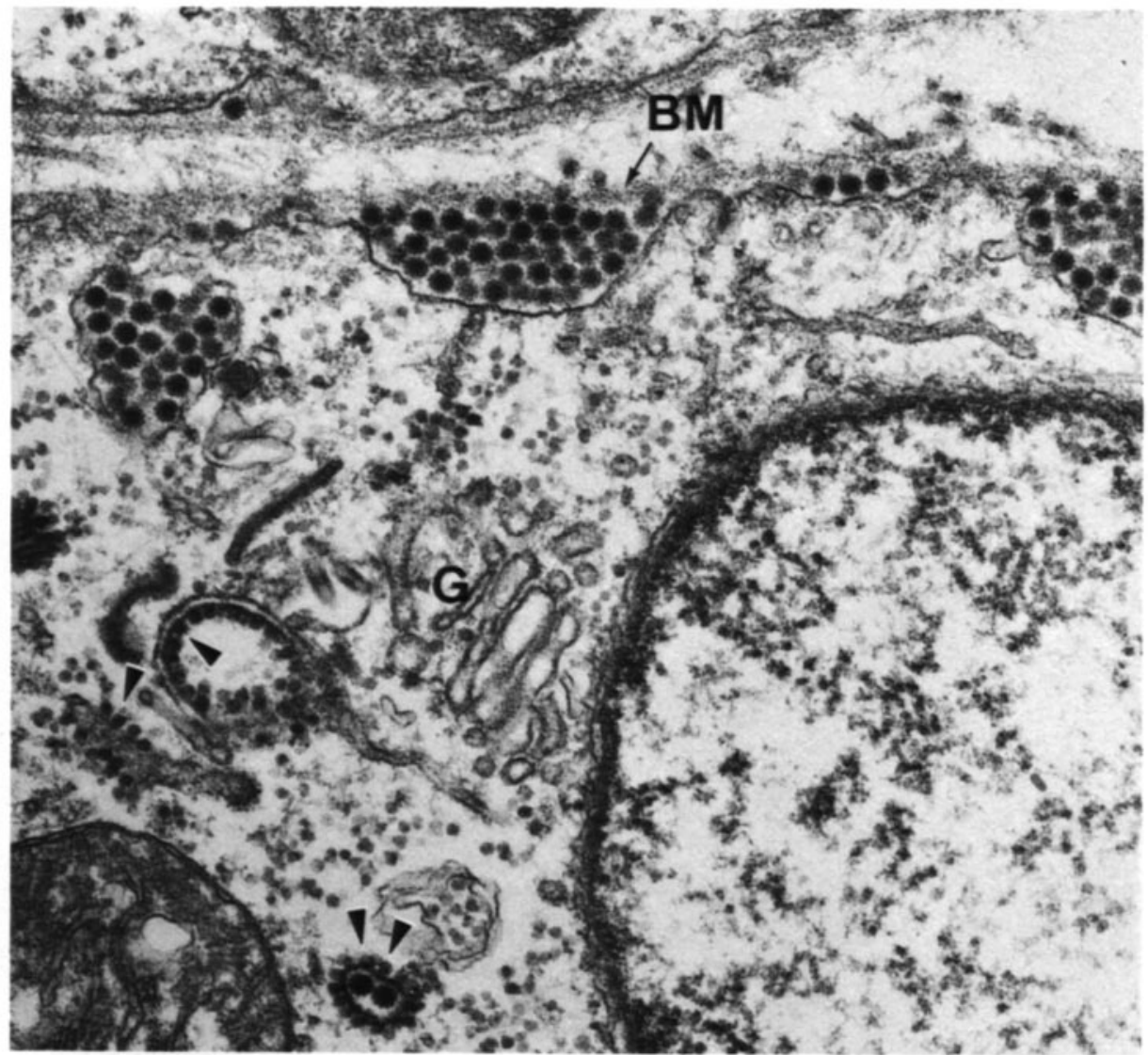

Fig. 8-4. SFV infection of a cell in the tongue of a mouse. Numerous virions are seen at the plasma membrane beneath the basement membrane $(B M)$. Near the Golgi apparatus $(G)$, NCs (arrowheads) are attached to smooth membranes in the cytoplasm in large numbers and mature virions lie within some of these vacuoles, which are called type 2 cytopathic vesicles (CPV-2). Magnification: $\times 40,000$.

(From Grimley and Friedman, 1970 a, with permission from University of Chicago Press)

be inhibited by host cell membrane proteins present in that location. Another hypothesis to explain the preferential binding of NCs to, and budding of virions from, the plasma membrane suggests that, because cleavage of p62 is required for virus budding, the location of the protease activity on the plasma membrane determines the budding site (Brown, 1980). However, recent evidence suggests that cleavage of p62 may occur in the Golgi like that of secretory proproteins and myxoand paramyxovirus glycoproteins (Rice and Strauss, 1981; Mayne et al., in press; Strauss and Strauss, in press). Cleavage can occur under conditions in which budding is inhibited, such as in medium of low ionic strength (Mayne et al., in press). Taking all these observations together, the site of Alphavirus budding probably depends upon both cleavage of p62 and presence in the membrane of adequate amounts of E1 and E2.

In permissive cell types, early after infection, synthesis of virus components appears to be balanced with the release of virions from the plasma membrane, so 

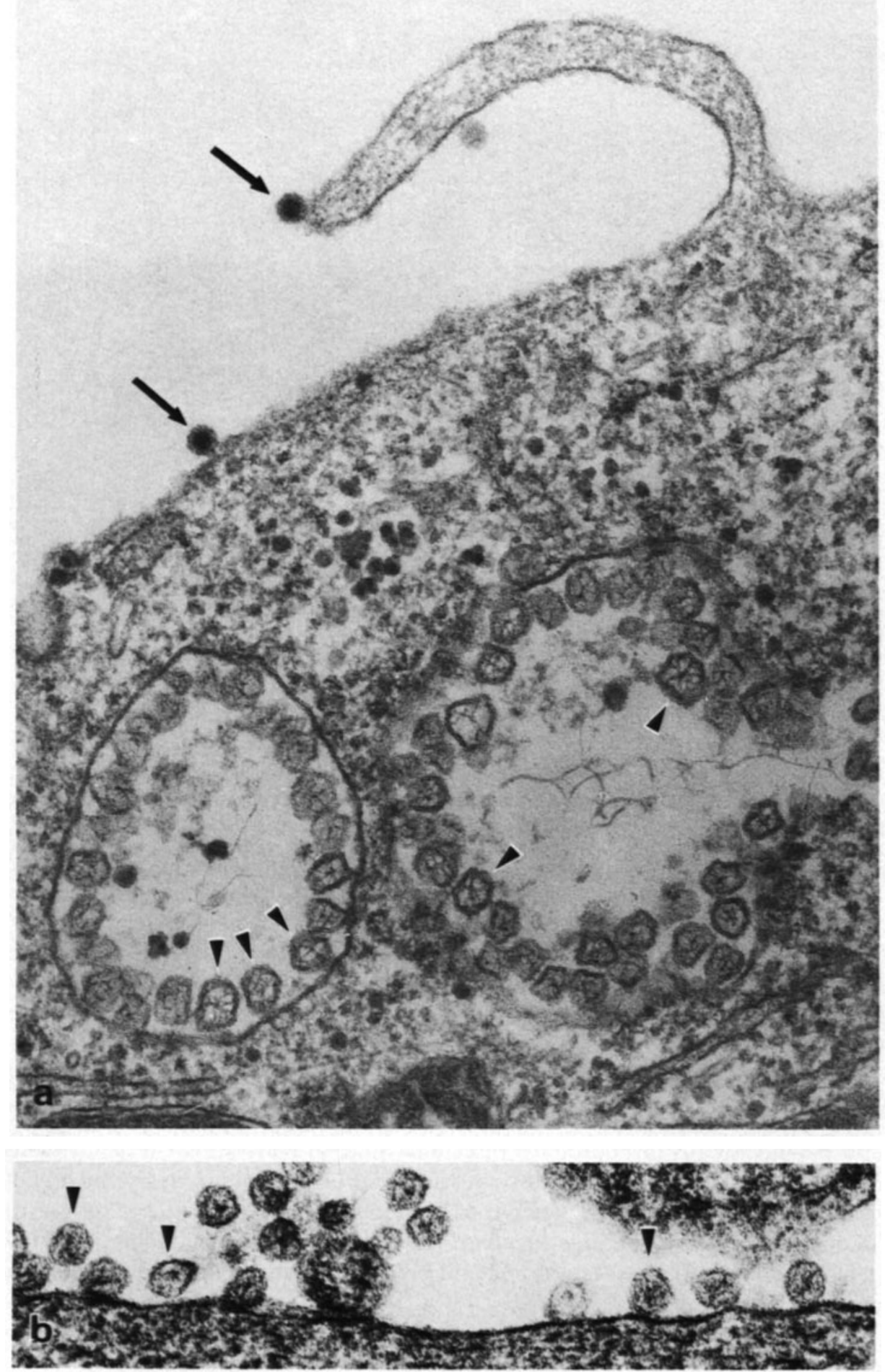
that little accumulation of virus components within the cells is observed. NCs are seen attached to the cytoplasmic side of the plasma membrane and virus buds form at the plasma membrane (Acheson and Tamm, 1967; Brown et al., 1972). Later, excess virus nucleocapsids accumulate in the cytoplasm attached to membrane vesicles.

Alphaviruses are released from the plasma membrane after budding and may be found in large numbers at the cell surface (Figs. 8-3, 8-4, and 8-5). Release of virions which bud into intracellular membranes, as in insect cells, is believed to be via fusion of virus-filled vesicles with the plasma membrane. Following release of virions, the binding of the NC to the viral envelope appears to be decreased, in comparison to the strong interactions which occur during the formation of the virus bud (Brown, personal communication). This might facilitate release of infecting NCs into cells following their entry through endocytic vesicles.

\section{Defective Assembly}

During the early stages of Alphavirus infection, often preceding formation of NCs, small $(60-70 \mathrm{~nm})$ membranous spheres containing fibrillar material have been observed attached to the lumenal wall of the RER and to the plasma membrane (Grimley et al., 1968, 1972, 1973; Fig. 8-5). These complexes are called type 1 cytopathic vesicles (CPV-1). Virus RNA synthesis is required for their formation and virus RNA has been localized in these vesicles by autoradiography (Grimley et al., 1968). It has been postulated that they are sites of virus RNA synthesis. Similar vesicles have been observed in cells infected with flaviviruses and coronaviruses (see Figs. 7-9 and 8-13).

Several different types of virus mutations affect the formation of virions (reviewed by Strauss and Strauss, 1980). Mutants in the C protein have been described which give rise to multiploid virions containing multiple NCs, possibly by faulty interaction with the glycoprotein. Such multiploid virions are also seen occasionally in infections with wild-type Alphaviruses (Fig. 8-3b). Ts mutants in the envelope proteins have been described which inhibit intracellular transport (Braha and Schlesinger, 1978; Erwin and Brown, 1980; Saraste et al., 1980 a, b). Sequencing of their cloned genes has suggested that intracellular transport depends upon a proper 3-dimensional configuration of the E1 glycoprotein (Arias et al., 1983). Mutants in which cleavage of p62 to E2 and E3 is prevented at the non-permissive temperature may permit the transport of E1 to the membrane and binding of the NC to the membrane, but no budding is observed until the cells are shifted to the permissive temperature (Brown, 1980). Similarly, attachment of NCs to the plasma membrane in the absence of virus bud formation was seen when a host-dependent mutant of

Fig. 8-5. Alphavirus budding and formation of type 1 cytopathic vesicles. (a) shows two virions budding at the plasma membrane (arrows) and demonstrates the type 1 cytopathic vesicles (CPV-1) seen in Alphavirus-infected cells shortly after infection. Spherical buds of membranes which contain electron-dense fibrillar material (arrowheads) are seen in smooth-walled vesicles in a cell infected with WEE. In panel (b), similar small membranous buds form at the plasma membrane of a cell infected with SFV. Magnifications: (a) $\times 70,000 ;(b) \times 107,500$ 


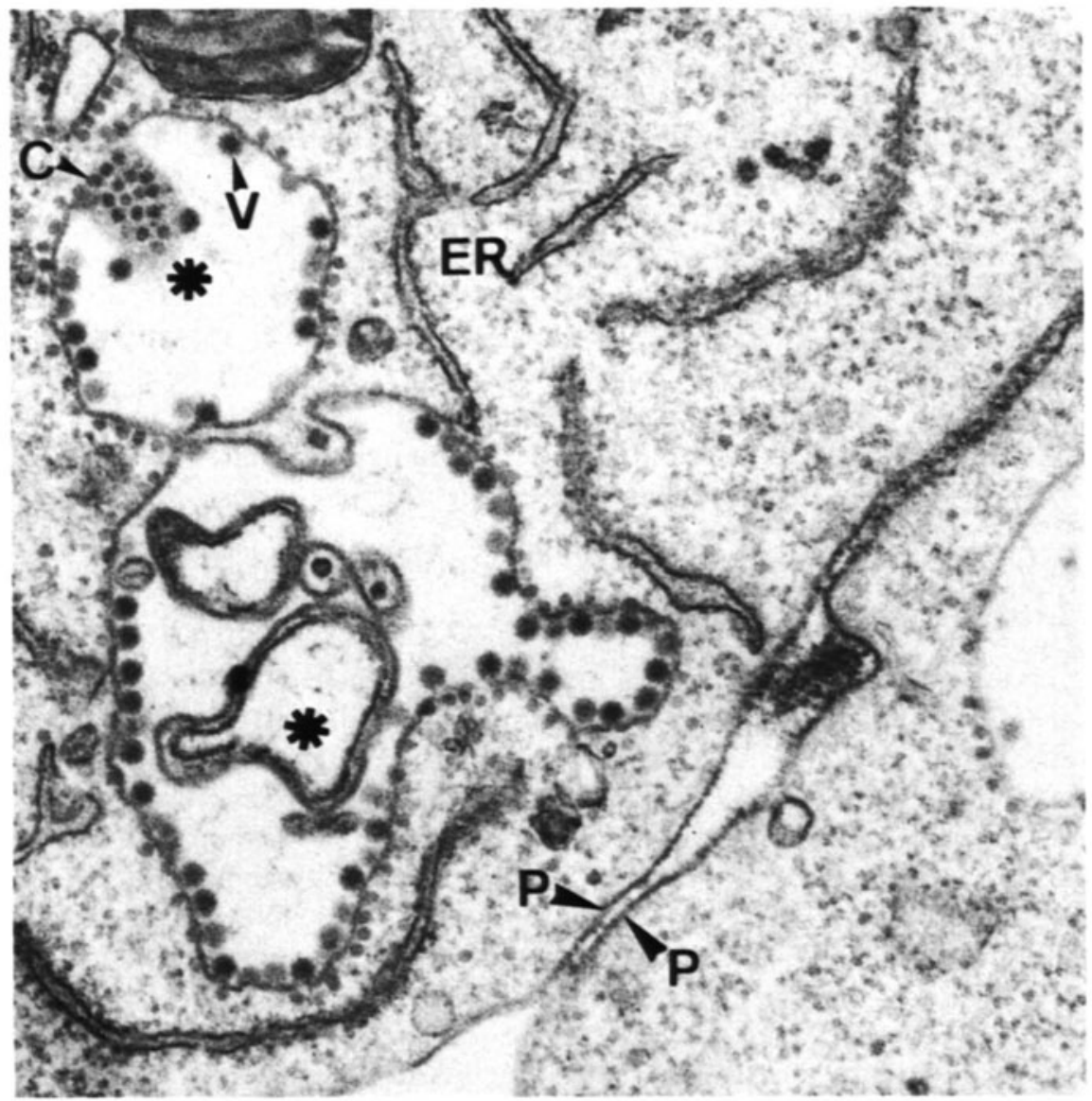

Fig. 8-6. An SFV-infected BHK cell treated with monensin, which arrests the intracellular transport of the viral glycoproteins and prevents the addition of terminal sugars to E1 and the cleavage of p62 to E2 and E3. In this cell, dilated Golgi cisternae (asterisks) contain many virions $(V)$, and many $N C s(C)$ are bound to the cytoplasmic side of the membranes. $E R$ is the endoplasmic reticulum and $P$ indicates the plasma membrane. Magnification: $\times 50,000$. (Figs. 8-6 and 8-7 courtesy of Dr. G. Warren from

Griffiths et al., 1983, with permission from the Rockefeller University Press)

Fig. 8-7. Cytochemical and immunoelectron microscopic identification of the region of the Golgi which shows capsid binding activity and virus budding in monensin-treated cells. (a) shows electrondense thiamine pyrophosphatase (TPPase) reaction product in the trans Golgi cisternae (large arrowhead) but not in the cisternae (asterisk) containing the budding virions (small dark arrowheads). (b) a frozen thin section shows that virions bud into the medial compartment of the Golgi into cisternae which can be labeled with gold-labeled antibodies to Ricinus communis agglutinin $1(R C A)$. The smaller gold marker ( $S F V$, thin arrows) indicates antibodies to virus spike glycoproteins on budding virions and on the lumenal side of the membrane (ME). NCs $(C)$ can be seen bound to the cytoplasmic side of the membrane. Magnifications: (a) $\times 39,000$; (b) $\times 110,000$ 

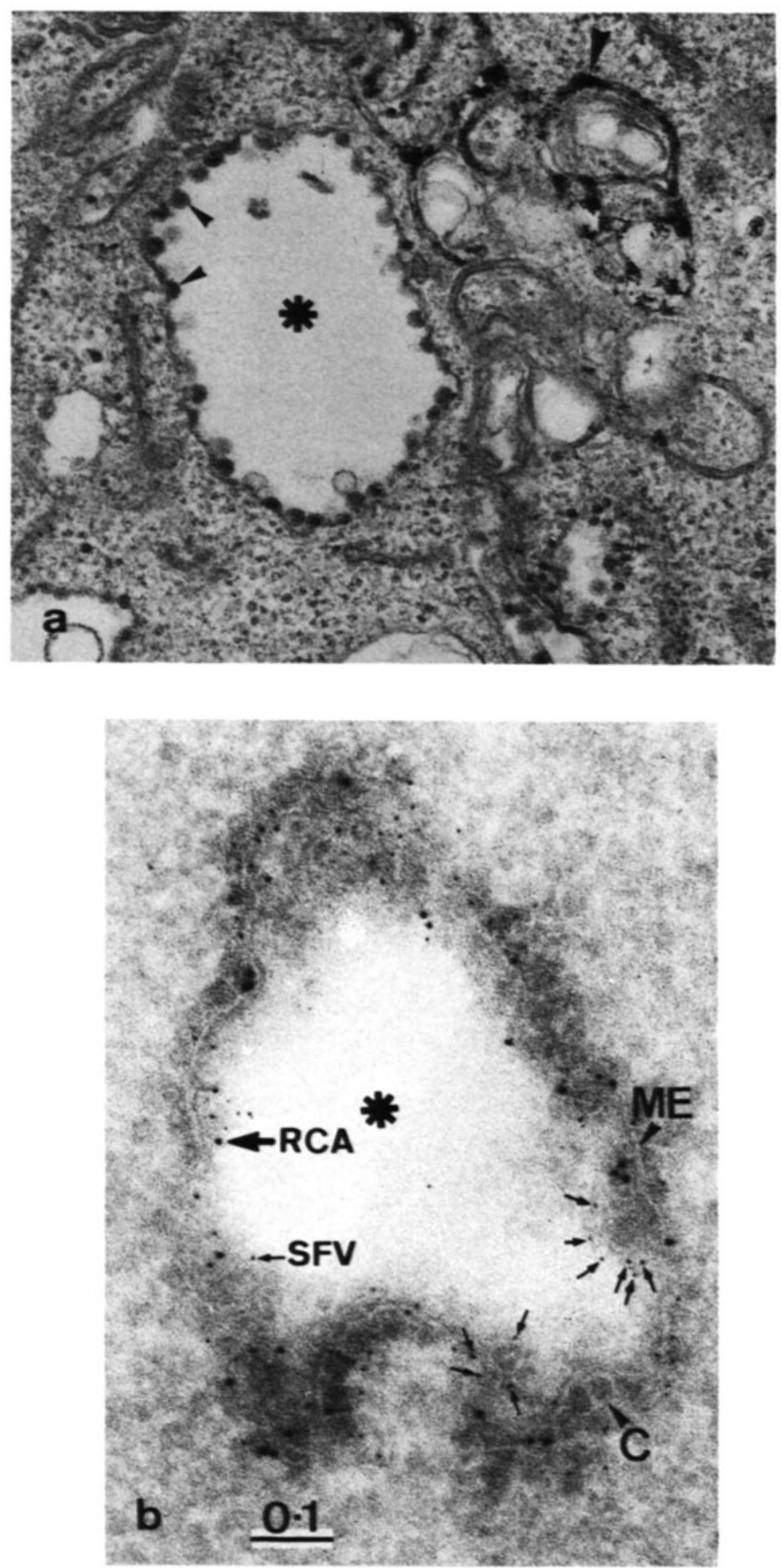
Sindbis virus was grown in cells from vertebrates. Although this mutant replicates normally in insect cells, an alteration in the E2 glycoprotein appears to be responsible for the inability of the mutant to bud from cells of vertebrates (Durbin and Stollar, personal communication).

Budding of Alphaviruses can be prevented by treatment of infected cells with high salt (Bell et al., 1978). Under these conditions, NCs are observed aligned under the plasma membrane and p62 is cleaved to yield E2 and E3, but no budding occurs. When the normal medium is restored, a brief period of highly synchronized virus budding and release occurs. This modulation of virus budding appears to be due to a charge-dependent alteration in the conformation of the p62 glycoprotein (Strauss et al., 1980). Brief treatment of cells with trypsin also inhibits Alphavirus budding (Adams and Brown, 1982).

Monensin has been used to study the intracellular transport of Alphavirus envelope proteins (Kääriäinen et al., 1980; Griffiths et al., 1983; Quinn et al., 1983). In BHK cells, monensin arrests the intracellular transport of $\mathrm{p} 62$ and $\mathrm{E} 1$ in the medial cisternae of the Golgi apparatus as shown by the elegant immunoelectron microscopic and cytochemical studies of Griffiths et al. (1983; Figs. 8-6 and 8-7). In these cells, large dilated vacuoles are formed which bind large numbers of NCs on

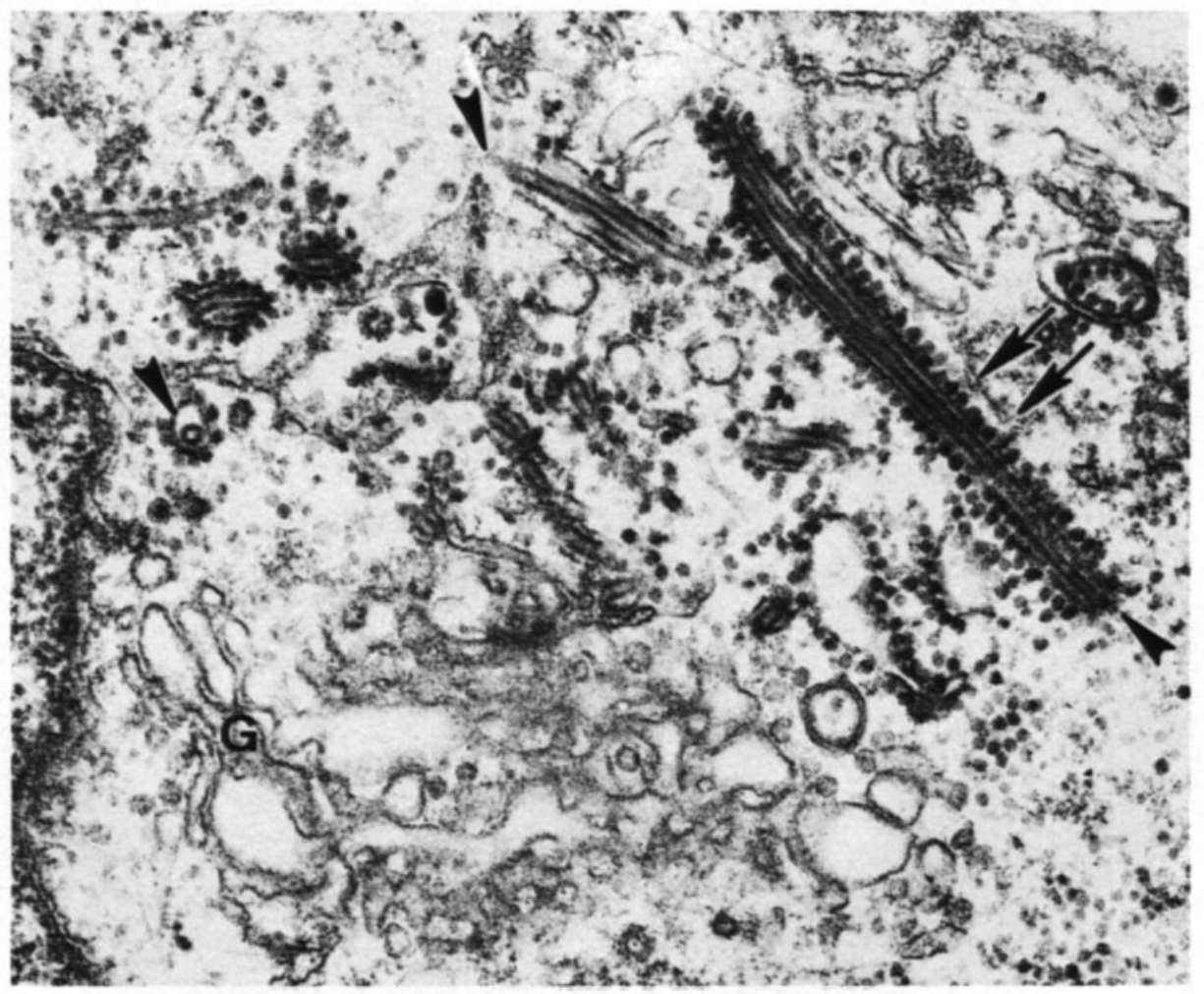

Fig. 8-8. A cell 24 hours after inoculation with SFV which contains long rigid tubules (arrowheads) within membranes to which numerous NCs (arrows) have bound. $G$ indicates the Golgi. Magnification: $\times 40,000$. (Courtesy of Dr. P. Grimley) 
their cytoplasmic surface. These vacuoles resemble the type 2 cytopathic vesicles (CPV-2) seen late in normal Alphavirus infections (Grimley and Friedman, $1970 \mathrm{a}$ and b; Grimley et al., 1973; Figs. 8-4 and 8-8). Possibly, accumulation of virus glycoproteins in the medial Golgi cisternae occurs late in infection and leads to the formation of the CPV-2. The monensin-induced membranes with their bound NCs can be isolated from other membranes of homogenized cells by density gradient ultracentrifugation (Quinn et al., 1983). Formation of virions can occur in these vacuoles (Figs. 8-6 and 8-7). It will be of great interest to determine whether virions formed in these vacuoles have p62 cleaved to E2 and whether they show normal infectivity. Long rigid tubules of unknown composition sometimes develop in CPV-2 late in the infectious cycle (Grimley and Friedman, 1970 b; Fig. 8-8).

In cells from invertebrates, in which persistent infection is much more common, virions frequently form in the RER or nuclear envelope, although early in infection some budding from the plasma membrane is also seen. Release of these intracellular virions from the cell has been postulated to result from fusion of vesicles filled with virions with the plasma membrane (Stollar, $1980 \mathrm{~b}$ ).

Several Alphaviruses have been reported to cause intranuclear accumulation of NCs (Murphy, 1980), but these have not yet been shown to contain Alphavirus antigens. The nucleus is not required for the maturation of Alphaviruses in vertebrate cells. However, in insect cells, some function of the cell nucleus is required for Alphavirus replication since enucleation prevented Alphavirus replication but not rhabdovirus replication (Erwin and Brown, 1983).

Although the binding of Alphavirus envelope proteins with NCs appears to be a very specific process, pseudotypes can be formed between different Alphaviruses (Strauss and Strauss, 1980; Strauss et al., 1983). For example, the glycoproteins of WEE and Sindbis viruses can substitute for each other in virions containing either genome. Thus, the glycoproteins of these two viruses are able to interact effectively with NC protein during virus budding. Further studies of the E1 and E2 glycoproteins of the parental viruses in such pseudotypes may clarify how soon after synthesis these two glycoproteins become associated and at what point they form spikes as they are transported through the cell. Pseudotypes of Alphaviruses with rhabdoviruses, defective Rous sarcoma virus and LDH virus have been formed, but these appear to contain only the NCs of the other virus with Alphavirus glycoproteins. No Alphavirus NCs with glycoproteins of other virus families have been detected. These observations suggest that the NCs of Alphaviruses exhibit stringent binding specificity for their homologous glycoproteins, whereas Alphavirus glycoproteins can be incorporated into virions of other viruses.

\section{Organization of the Virion}

A model describing the replication, transcription and assembly of Alphaviruses is shown in Fig. 8-9. Postulated structural relationships between virion components are shown in Fig. 8-10. Further studies on the morphology of Alphaviruses will probably focus upon the formation and symmetry of the NC, specific domains in the structural proteins which interact with RNA, lipid, and other proteins or which 


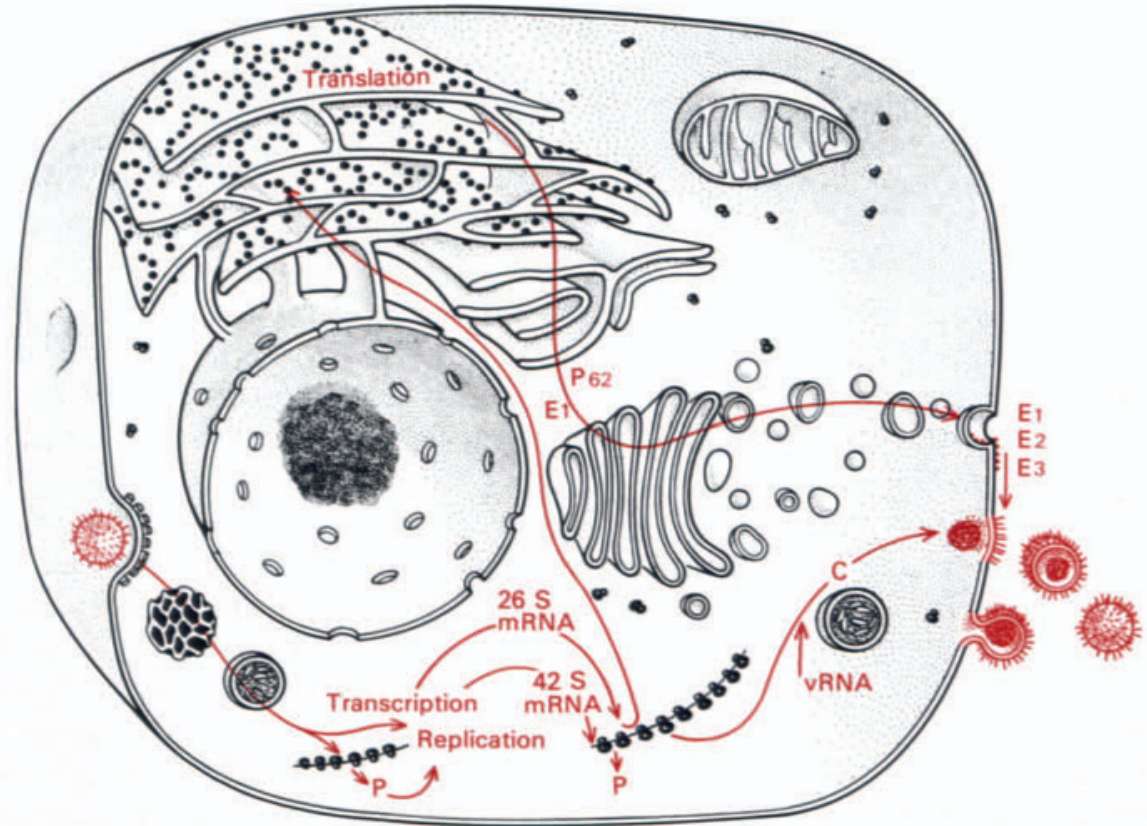

Fig. 8-9. A model summarizing the events in the replication, transcription and assembly of Alphaviruses. Virions enter the cell through clathrin-coated vesicles and virus RNA is released into the cytoplasm by fusion of the virus envelope with the endosomal membrane. RNA-dependent RNA polymerase is synthesized using the genomic RNA as mRNA. Primary transcription yields a full length negative-stranded RNA which is copied to make genomic RNA and 26S RNA. The structural proteins are translated from the polycistronic $26 \mathrm{~S}$ RNA. The NC protein, $C$, is made first on free polysomes and the growing polypeptide chain is cleaved to reveal a signal sequence which inserts into the RER. Then, p62 and E1 are made on membrane-bound polysomes, glycosylated, acylated, and transported through the Golgi to the plasma membrane. Cleavage of p62 to yield E2 and E3 is a late step which occurs in association with virus budding.

direct intracellular transport of these proteins (Arias et al., 1983). Molecular genetic techniques including formation of chimeric proteins or proteins with site-specific mutations are expected to provide greater insight into Alphavirus morphogenesis.

\section{Flaviviruses}

\section{Introduction}

The Flaviviruses are a group of more than 50 viruses which are similar biochemically and antigenically (Russell et al., 1980). The group includes mosquito-borne viruses such as yellow fever and dengue viruses, tick-borne viruses including tick-borne encephalitis, and non-arthropod-borne viruses such as Dakar bat virus. Where they have been studied, these viruses are all small and enveloped with positive-stranded RNA genomes, capsids with cubic symmetry, and three structural protein species, 


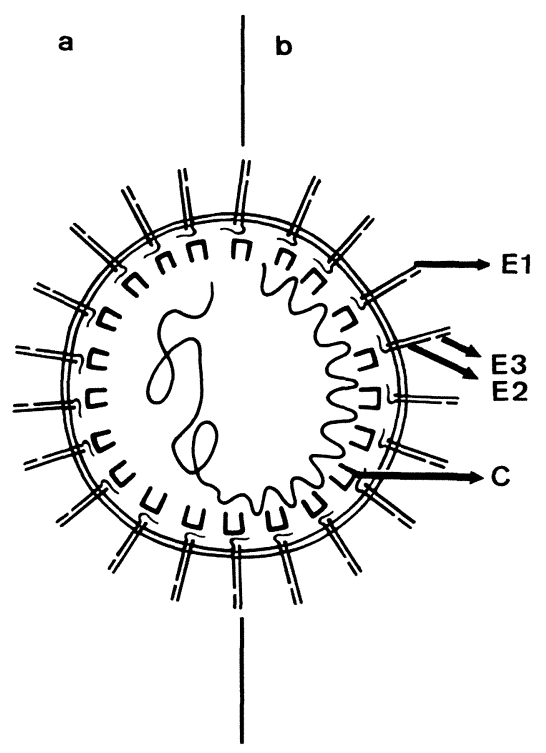

Fig. 8-10. A model of the organization of the Alphavirus SFV. The virus envelope contains three glycoproteins. E3 is peripherally located and E1 and E2 are transmembrane glycoproteins. The cytoplasmic domain of $\mathrm{E} 2$ interacts with the $\mathrm{C}$ protein of the icosahedral NC, causing an icosahedral arrangement of peplomers on the viral envelope. The arrangement of the genomic RNA within the virion is not known. (a) is a model in which the RNA is free within the NC and (b) is a model in which the RNA interacts in a regular manner with $C$ protein

one of which is a glycoprotein. The virions are spherical particles $36-44 \mathrm{~nm}$ in diameter (Murphy, 1980; Fig. 8-11a and b). The peplomers (spikes) are clearly resolved in virions isolated from sucrose gradients and they form a thin layer around the virion. On some flaviviruses, ring-like structures $7 \mathrm{~nm}$ in diameter are observed (Fig. 8-11c and d). The virus core is an electron-dense spherical structure $27 \mathrm{~nm}$ in diameter.

\section{Molecular Organization}

The Flaviviruses have not been as extensively studied by molecular biological techniques as Alphaviruses for several reasons. They have a latent period of at least 12 hours and they do not shut off host cell macromolecular synthesis (Westaway, 1980). Thus pulse-labeling experiments early in the infectious cycle do not yield clear results. Finally, the virions are somewhat fragile and difficult to characterize. Nevertheless, significant information about the structural proteins is now available, and cloning of Flavivirus genes is in progress.

The replication of Flaviviruses has been reviewed by Schlesinger (1977) and Westaway (1980). The Flavivirus genome is a single stranded $4 \times 10^{6}$ dalton RNA molecule of positive or message sense. It is capped at the $5^{\prime}$ end, but is not polyadenylated (Wengler and Wengler, 1981). Recent evidence (J.Dalrymple, 

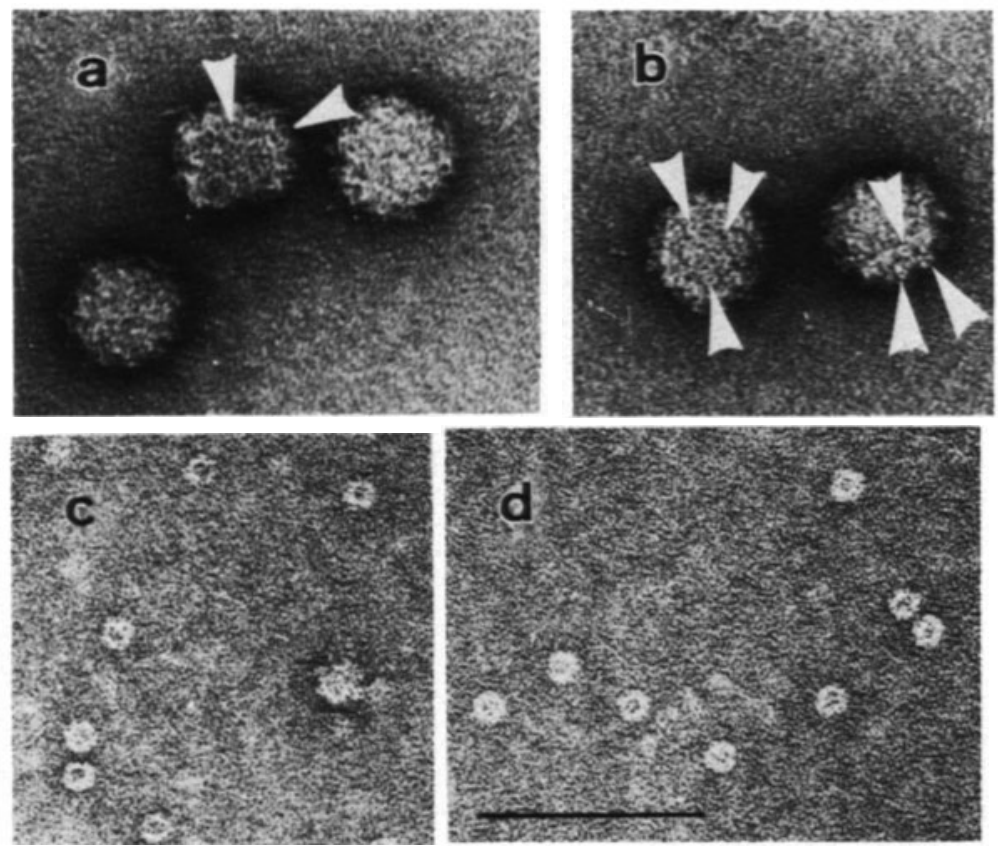

Fig. 8-11. Structure of flavivirion and subviral particles. (a) and (b) show that dengue virions are spherical particles which have circular subunits (arrowheads) $7 \mathrm{~nm}$ in diameter on the surface of the virus envelope. Slowly sedimenting hemagglutinin (SHA) particles, which are released during viral infections, are shown in (c) and (d). These contain V3, V1 and NV2 proteins in a $14 \mathrm{~nm}$ ring-shaped structure. Magnification: $\times 140,000$. (Figs. 8-11a-d; courtesy of Dr. W. Brandt, from Murphy, 1980; with permission from Academic Press)

personal communication) shows that the $3^{\prime}$ ends of at least three different Flaviviruses share a sequence of 9 to 22 nucleotides. The genes for the structural proteins are located at the $5^{\prime}$ end of the virus genome, and the NC protein is the $5^{\prime}$ terminal protein (J.H. Strauss, personal communication).

Replication and transcription of Flaviviruses differ markedly from Alphaviruses (Westaway, 1980; Strauss and Strauss, 1983). Within flavivirus-infected cells, the only virus-specific RNAs to be identified are 42-44S single stranded RNA and a $20 \mathrm{~S}$ double stranded replicative intermediate. No subgenomic mRNAs have been detected in infected cells.

No virion-associated RNA-dependent RNA polymerase activity has been characterized, although it appears likely, by analogy with Alphaviruses, that several non-structural proteins may participate in this function in the infected cells. The virus replicase/transcriptase activity appears to be associated with membranes (Westaway and $\mathrm{Ng}, 1980$ ). Autoradiography shows that virus RNA synthesis occurs in a sharply circumscribed area of the cytoplasm near the nucleus (Matsumura et al., 1971).

There are three structural polypeptides in Flaviviruses whose properties are summarized in Table 8-2 (Russell et al., 1980). The exact locations and interactions of these proteins within the virion have not been determined as precisely as for the Alphaviruses. 
Table 8-2. Structural Proteins of Flaviviruses

\begin{tabular}{lll}
\hline $\begin{array}{l}\text { Usual } \\
\text { name }\end{array}$ & $\begin{array}{l}\text { Apparent MW } \\
\mathrm{X} 10^{-3}\end{array}$ & $\begin{array}{l}\text { Known or putative } \\
\text { function }\end{array}$ \\
\hline V2 & 14 & $\begin{array}{l}\text { NC protein } \\
\text { Non-glycosylated membrane protein } \\
\text { V1 }\end{array}$ \\
V3 & $51-59$ & $\begin{array}{l}\text { May function as M protein } \\
\text { Peplomeric glycoprotein } \\
\text { Hemagglutinin } \\
\text { Binds to cell surface receptors }\end{array}$ \\
\hline
\end{tabular}

Adapted from Westaway, 1980.

(1) V2 (MW: $14 \mathrm{~K}$ ) is the NC protein. It binds to virus RNA and forms the NC which lies within the viral envelope.

(2) $V 1(\mathrm{MW}: 8 \mathrm{~K})$ is a non-glycosylated membrane protein which appears to lie beneath the membrane in intact virions, since it cannot be labeled with ${ }^{125} \mathrm{I}$. V1 may function like an $\mathrm{M}$ protein. Amino acid sequences deduced from cloned flavivirus genes suggest that V1 is probably an integral membrane protein derived from a glycosylated precursor by proteolytic cleavage (J. H. Strauss, personal communication).

(3) V3 (MW: $51 \mathrm{~K}-59 \mathrm{~K}$ ) is a glycoprotein which comprises the peplomers. It is the virus hemagglutinin and probably binds the virus to receptors on host cells. How V3 interacts with V1 and V2 is not known.

(4) Non-structural proteins. Westaway (1980) summarizes the data on many non-structural virus-specific proteins in Flavivirus-infected cells. Work on the identification of structural relationships and functions of these proteins is in progress.

\section{Protein Synthesis, Transport and Post-Translational Modifications}

Fluorescent antibody labeling (Fig. 8-12) shows that the non-structural proteins are made in the perinuclear area. Then the structural proteins become dispersed through the cytoplasmic membranes, while the non-structural proteins remain associated with the perinuclear membrane (Cardiff et al., 1973). The first morphological change seen in cells infected with Flaviviruses is proliferation of smooth and granular membranes in the perinuclear area (Baruch, 1963; Leary and Blair, 1980; Murphy, 1980; Figs. 8-13 and 8-14). Possibly these intracellular membranes are required for Flavivirus RNA polymerase activity.

Cell fractionation studies suggest that all of the virus proteins are synthesized in association with cellular membranes (Westaway, 1980) and that translation of virus structural and non-structural proteins occurs on heavier membranes than translation of cellular proteins (Westaway and $\mathrm{Ng}, 1980$ ). This is markedly different from the other enveloped RNA viruses in which only the glycoproteins are synthesized on membranes. Preliminary in vitro translation studies have shown that 

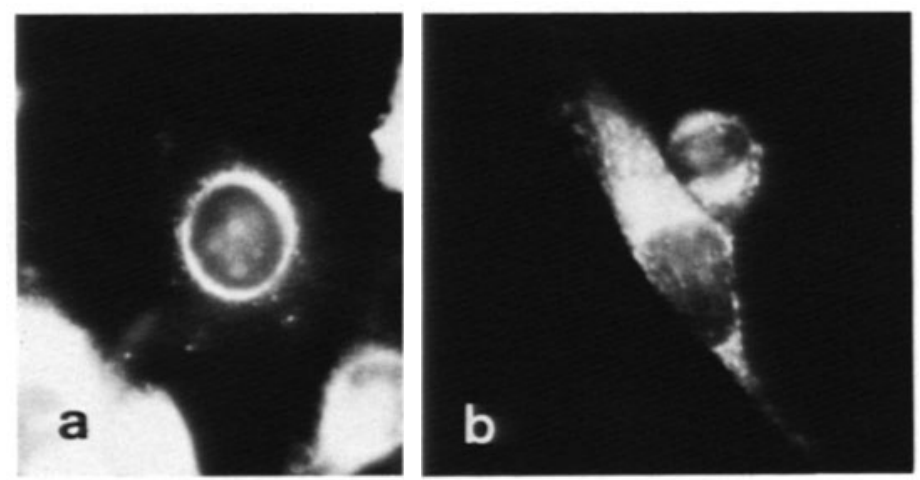

Fig. 8-12. Distribution of the antigens of the Flavivirus dengue-2 in infected cells. In (a), fluorescent labeling with antibody to non-structural proteins (soluble complement-fixing antigen, SCF) yields sharply demarcated perinuclear staining, whereas labeling with antibody to virion structural proteins (rapidly sedimenting hemagglutinin) (b) gives diffuse, granular cytoplasmic staining. Magnification: $\times 1,470$. (Courtesy of Dr. W. Brandt, from Cardiff $e$ al., 1973, with permission from American Society for Microbiology)

the 42S RNA from infected cells can direct the synthesis of a large polyprotein which contains sequences of some of the structural proteins (Wengler et al., 1979).

Pulse labeling studies have not yet yielded a clear picture of the precursorproduct relationships of the virus-specific proteins. These studies and pactamycin mapping studies suggest that for Flaviviruses, unlike other RNA viruses, there may be multiple internal initiation sites for translation (Westaway, 1980). Alternatively, proteolytic cleavage of a polyprotein may be required to generate the structural proteins. Cloning of a Flavivirus genome and determination of its nucleotide sequence is likely to resolve this central question in Flavivirus replication.

Only the V3 protein is glycosylated. It has been detected on the plasma membrane of infected cells by immunofluorescence and immunoelectron microscopy.

\section{Assembly of Virus Components}

The assembly of Flaviviruses has not been extensively studied at the molecular level. The NCs from disrupted virions have been visualized in negatively stained or shadowed preparations. Because of the small size, lability and indistinct capsomers of Flavivirus NCs, it has been difficult to determine the precise geometry of the cubical symmetry of the NCs.

In contrast to Alphaviruses, Flaviviruses have no free NCs in infected cells. Isolated Flavivirus NCs are $27 \mathrm{~nm}$ in diameter, significantly smaller than Alphavirus NCs and similar to the size of ribosomes. Possibly, some of the rough membranes seen in Flavivirus-infected cells are not RER, but membranes with bound Flavivirus NCs. This question may be resolved by immunoelectron microscopy.

Virtually nothing is yet known about the way in which the NC protein, V2, binds to the genomic RNA or to other virus structural proteins. Indeed, as Murphy points out in his comprehensive review of Flavivirus morphogenesis (1980), it has 


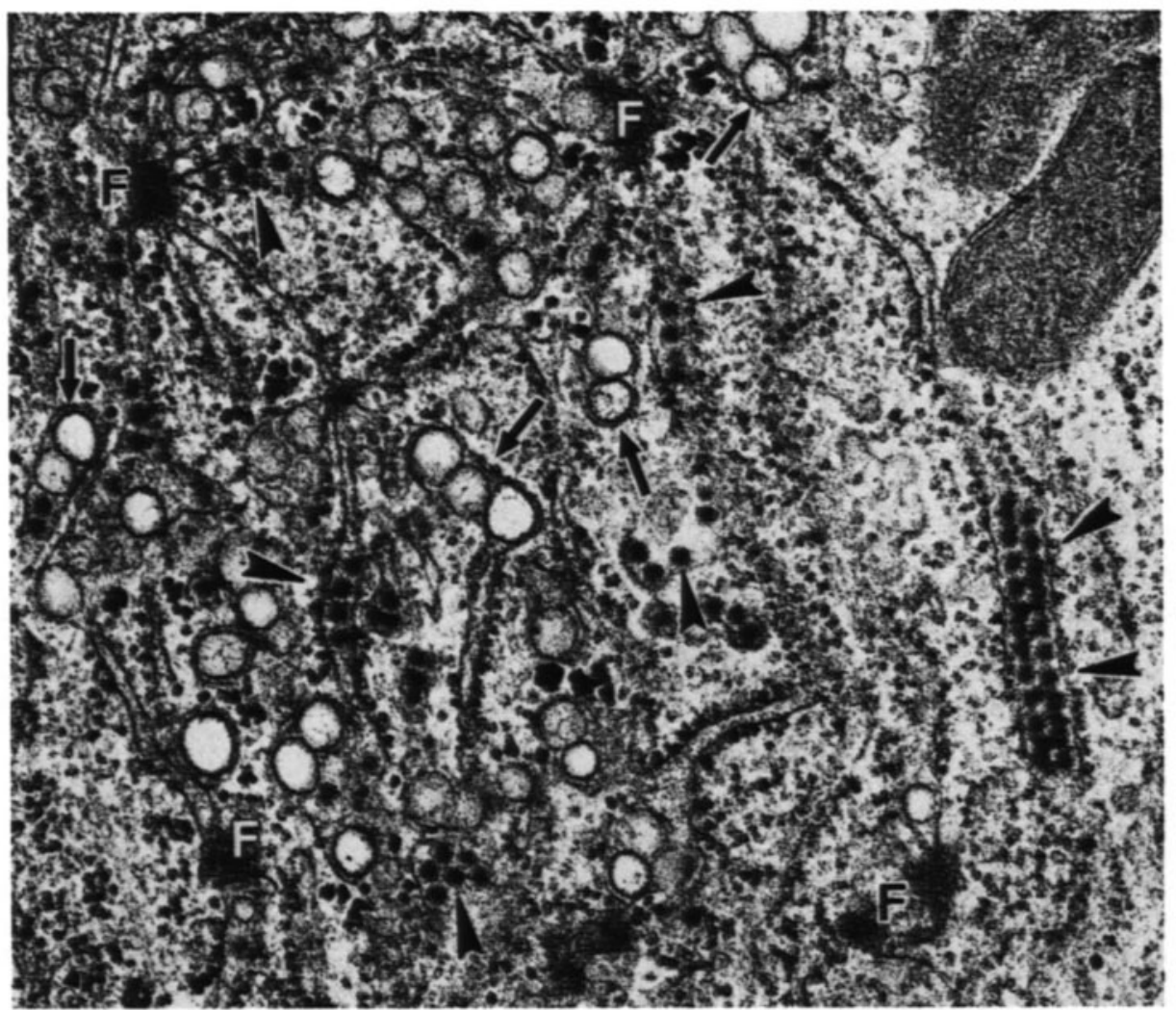

Fig. 8-13. Cells infected with the Flavivirus, yellow fever virus. Enveloped virions are seen in the lumen of the RER (arrowheads) both singly and in tightly packed arrays. The RER also contains membranous spheres (dark arrows) called type 1 cytopathic vesicles (CPV-1) which contain fine electron-dense filaments. Flavivirus-infected cells frequently contain dense filamentous material $(F)$ in association with extensive rough and smooth intracytoplasmic membranes. Magnification: $\times 23,000$. (Figs. 8-13 to 816 , are courtesy of Dr. P. Grimley)

not yet been definitely shown that Flaviviruses mature by budding like other enveloped RNA viruses. Budding certainly is the most probable mechanism for the formation of a virion with this structure, but thin sections of Flavivirus-infected cells do not clearly show partially formed virus buds either on the intracellular membranes or the plasma membrane (Deubel et al., 1981; Figs. 8-13 to 8-15), although some observers have claimed to see rare budding virions (Matsumura et al., 1977; Murphy, 1980; Bhatt et al., 1981). As an alternative to budding from membranes, assembly of virions from components within cytoplasmic vesicles has been proposed (Leary and Blair, 1980). This seems unlikely, in light of information about the assembly of other enveloped RNA viruses. Failure to visualize virus budding could be explained if budding were a very rapid event. The very small size of the Flavivirion may also be a factor which limits ability to visualize budding virions. Since fixatives such as glutaraldehyde and osmium tetroxide, do not fix lipids rapidly, limited flow of membrane components is possible even after fixation. This could allow virus buds to be flattened or pinched off after fixation. Indeed, 
images of fusing pinocytic vesicles at the plasma membrane were rarely observed until the development of fast-freezing (see Chapter 1), a new technique which freezes cells in milliseconds. This technique might be useful for visualizing budding of Flaviviruses.

Regardless of their mechanism of formation, it is clear that Flaviviruses are released into RER, Golgi (Baruch, 1963; Blinzinger, 1972; Figs. 8-13 to 8-15) and probably also from the plasma membrane (Murphy, 1980). In cultures of vertebrate cells infected with Flaviviruses, large numbers of virions in tightly packed hexagonal arrays or in crystals have frequently been observed at plasma membranes, although

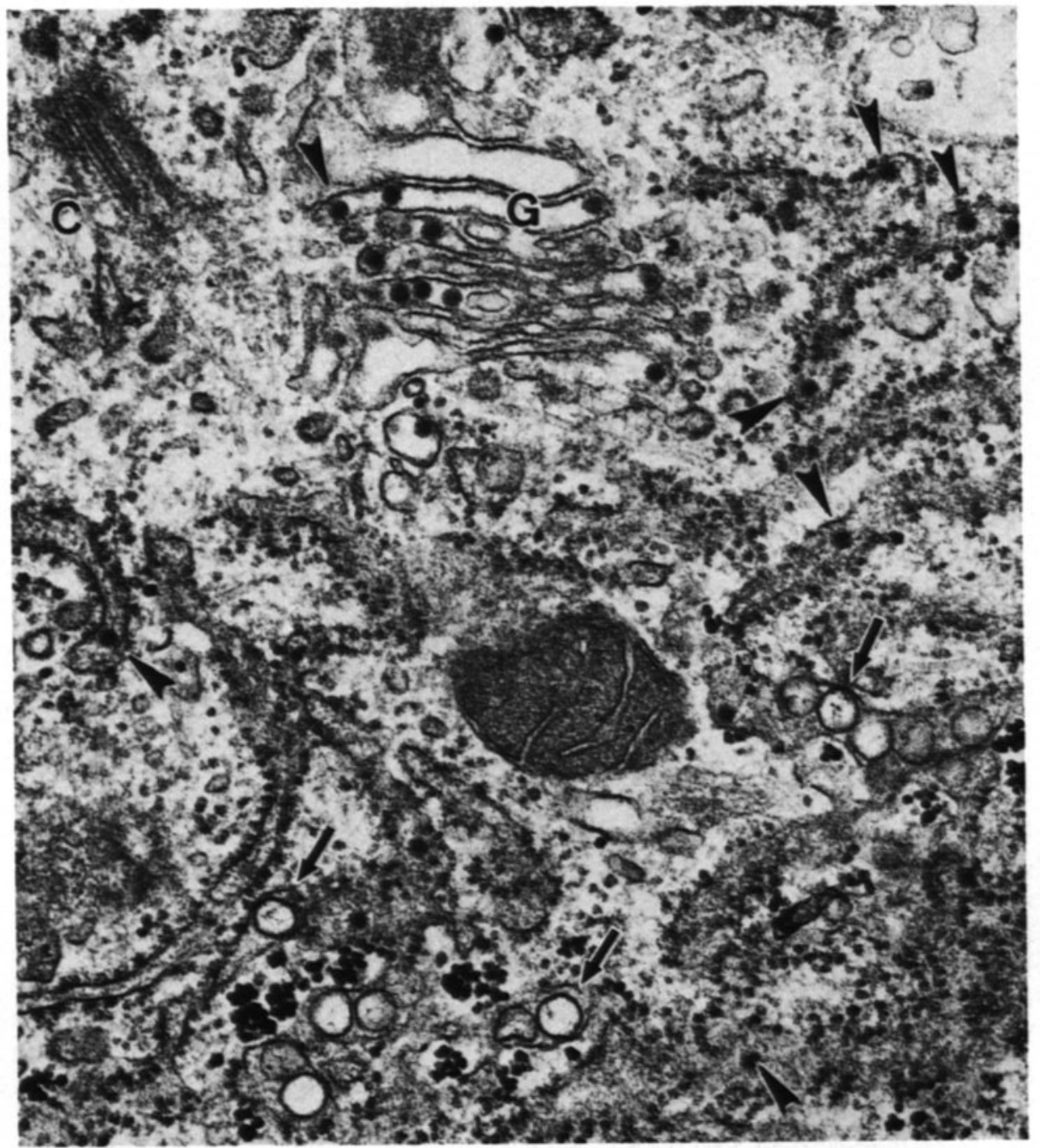

Fig. 8-14. A cell infected with St. Louis encephalitis virus (SLE). Enveloped virions are seen in the Golgi cisternae $(G)$ and in the lumen of the RER (small arrowheads) and CPV-1 are seen in the RER (arrows). In Flavivirus-infected cells, budding virions have almost never been visualized. $C$ indicates a centriole. 
no budding virions were observed (Fig. 8-15a). In insect cells, large numbers of Flavivirions may accumulate within RER lamellae (Sinarachatanant and Olson, 1973; Deubel et al., 1981; Fig. 8-15b). What factor(s) determines the location of virus development in vertebrate and arthropod cells infected with Flaviviruses is not known.
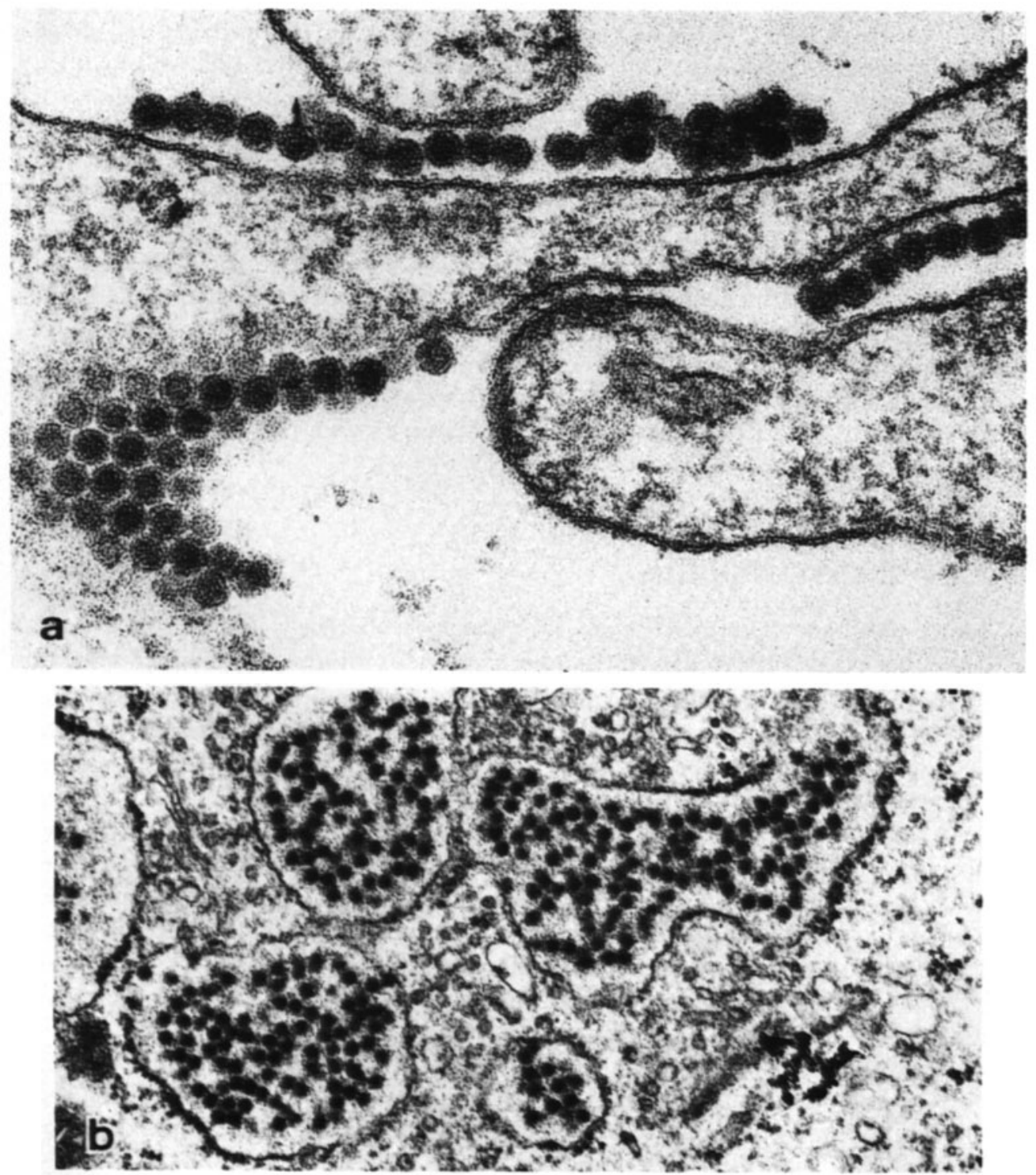

Fig. 8-15. Comparison of Flavivirus infection in cells from vertebrates and invertebrates. In (a), yellow fever virions are seen in tightly packed hexagonal array on the plasma membrane of a cell from a vertebrate and some virions are also seen in intracytoplasmic vacuoles as observed with other viruses (Figs. 8-13d, 8-14). In contrast, in a mosquito cell, large numbers of yellow fever virions accumulate in the lumen of the RER (b) and fewer virions are seen at the plasma membrane. Magnifications: (a) $\times 115,000$; (b) $\times 40,000$ 
The intracellular virions of dengue type- 2 virus and Japanese $B$ encephalitis virus have been isolated from disrupted cells and compared with released virions (Shapiro et al., 1972 and 1973). The intracellular virions contained V3, V2, and NV2, a non-structural protein. These virions, of much lower specific infectivity than the released virions, may represent precursors to the infectious released virions (Westaway, 1980).

Two mechanisms for release of intracellular virions from infected cells have been proposed (Schlesinger, 1977; Murphy, 1980; Westaway, 1980). Virus-filled vacuoles may migrate through the cytoplasm to fuse with the plasma membrane or virions may be released by lysis of infected cells (Demsey et al., 1974). Release of virions through membranous channels connected to the external medium has been demonstrated by serial thin sectioning, but cell lysis may also release some intracellular virions.

Viruses which bud from the plasma membrane often show preferential budding from the apical or basolateral domains of the membrane of epithelial cells (Rodriguez-Boulan, 1983). Although Flaviviruses appear to form at intracellular membranes, some polarity in virus release from epithelial cells has been detected. In insect salivary gland, SLE virus release occurred preferentially from the apical region of the cell rather than from the basolateral region (Whitfield et al., 1973).

\section{Defective Budding}

Some membrane vesicles, like the CPV-1 vesicles seen in cells infected with Alphaviruses, have been observed in Flavivirus-infected cells (Murphy, 1980; Fig. 8-13). The function of these small vesicles within cytoplasmic membranes is not known and the delicate strands of material in the vesicles have not been characterized. By analogy to Alphaviruses (Grimley et al., 1972), these structures might play a role in RNA synthesis.

A unique striated filamentous inclusion has been observed in Flavivirusinfected cells by many investigators (McGavran and Easterday, 1963; Blinzinger $e t$ al., 1971; Matsumura et al., 1977; Oshiro et al., 1978; Bhatt et al., 1981; Grimley and Henson, 1983; Fig. 8-16a and b). The inclusion consists of long fibers or sheets of electron-dense strands in a crystalline pattern with fine, short filaments which are perpendicular to the long strands and regularly spaced along them. The composition of these filaments is not known.

The proliferation of membranes in Flavivirus-infected cells sometimes leads to the formation of complex tubular cytoplasmic inclusions. Fig. 8-16c shows such tubular inclusions in a tightly packed honeycomb pattern. The composition of these tubules has not been determined.

In preparations of Flaviviruses, a subviral component has been identified and designated the slowly sedimenting hemagglutinin (SHA). When isolated by density gradient ultracentrifugation, the 70S SHA was found to consist of doughnut shaped structures $14 \mathrm{~nm}$ in diameter (Smith et al., 1970; Fig. 8-11c and d) and to contain V3, V1, and NV2 proteins. The doughnut-shaped structures on the surface of Flavi- 

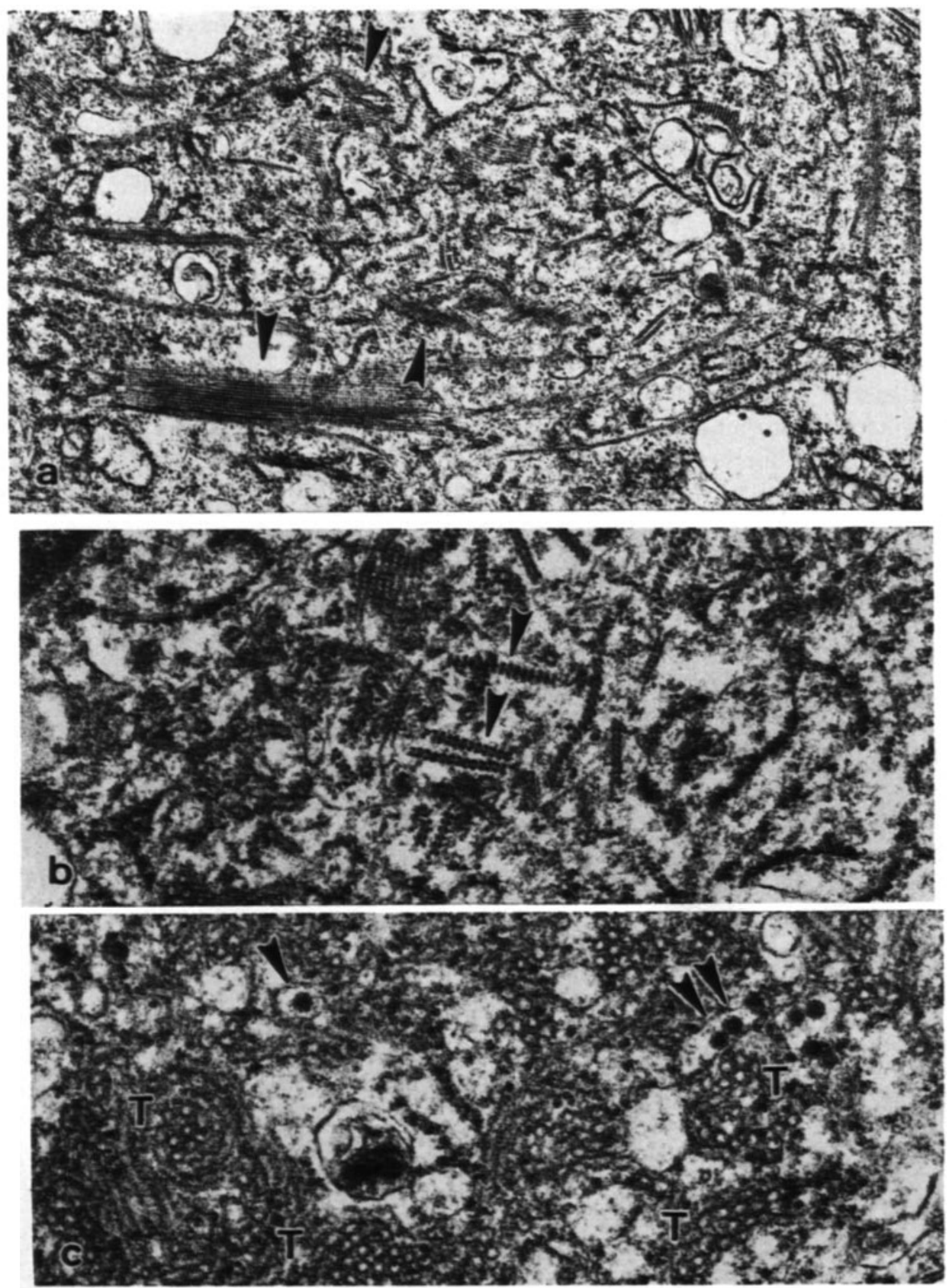

Fig. 8-16. Unique intracytoplasmic inclusions in cells infected with Flaviviruses (a). In cells infected with SLE virus, the cytoplasmic matrix is filled with electron-dense, filamentous material in sheets or bundles (arrowheads) (b). At higher magnification, fine, electron-dense cross-striations are seen on the filaments in a regular pattern which forms a lattice on the sheets and a beaded appearance on the filamentous bundles (arrowheads) . (c) shows cytoplasmic inclusions of tightly packed tubules $(T)$ in a honeycomb pattern. The compositions of the filamentous and tubular inclusions are unknown.

Virions are seen in vacuoles (arrowheads). Magnifications: (a) $\times 20,000$; (b) and (c) $\times 47,500$

10 Dubois-Dalcq et al., Assembly 
viruses in negatively stained preparations are only $7 \mathrm{~nm}$ in diameter (Fig. 8-11a and b), and are therefore probably different from the SHA. It is not clear whether the SHA is derived from virions or from cellular membranes which have been altered by the insertion of virus proteins.

A second subviral particle found in Flavivirus preparations from brain or serum of infected animals is a $4 S$ "soluble" complement-fixing antigen (SCF) which is highly antigenic. The SCF apparently consists of non-structural virus antigens. The mechanisms of formation and release of this SCF are not yet understood.

\section{Organization of the Virion}

The foregoing discussion of Flavivirus morphogenesis illustrates the mysteries which still surround the formation and replication of these medically important viruses. A model to illustrate present hypotheses about Flavivirus replication and assembly is shown in Fig. 8-17. A schematic model showing possible organization of Flavivirus structural proteins is shown in Fig. 8-18.

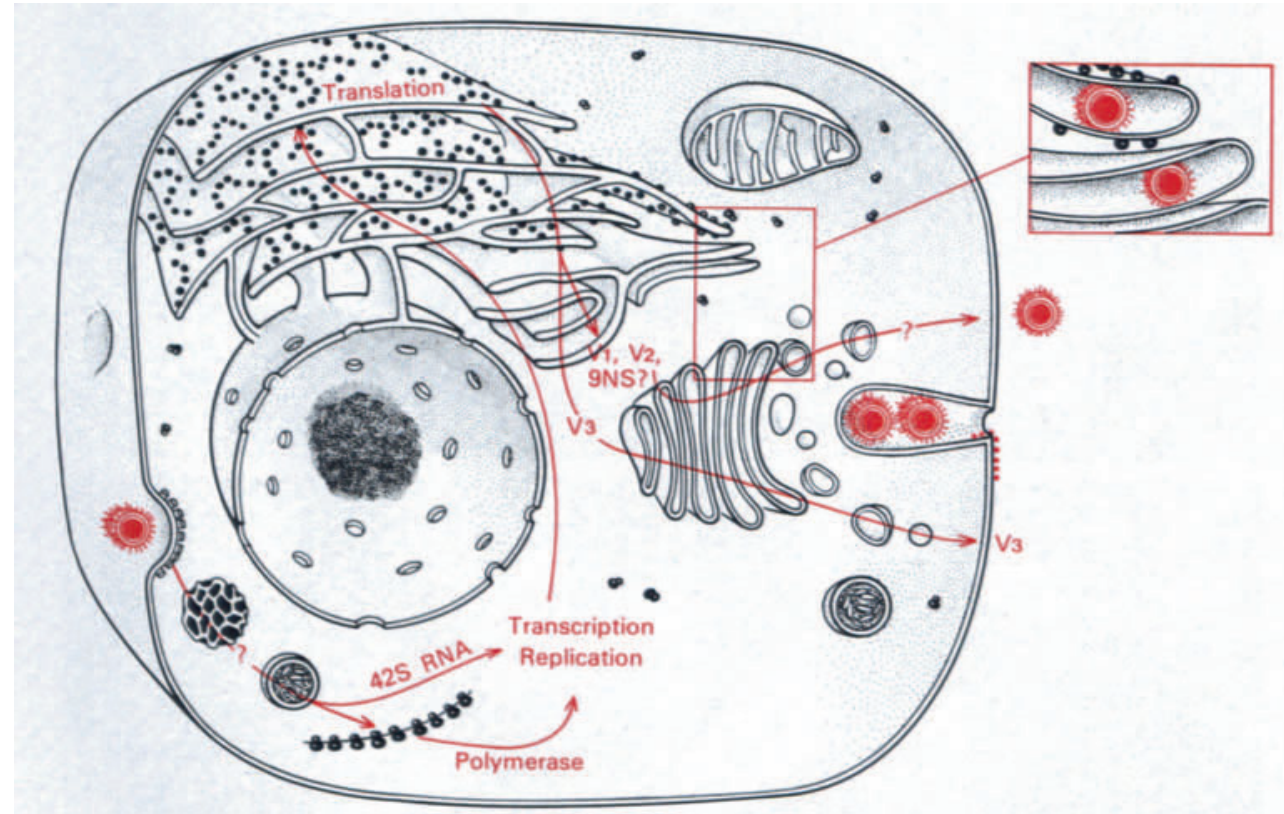

Fig. 8-17. A model summarizing current concepts of the replication, transcription and assembly of Flaviviruses. It is not clear whether virions are taken up by clathrin-coated vesicles. The virus genomic RNA acts as mRNA to direct the synthesis of RNA-dependent RNA polymerase. Only full-length negative and positive strands of RNA are found in Flavivirus-infected cells. Translation of all 3 structural and 9 non-structural proteins of Flaviviruses appears to occur on membrane-bound polysomes. Nonstructural proteins appear to remain in the perinuclear area while the peplomeric glycoprotein V3 is transported through the Golgi to the plasma membrane. Late in infection, many of the virus proteins are found in association with the plasma membrane. No NCs have been observed in the cytoplasm of infected cells. Although enveloped virions are found in the lumen of the RER and Golgi (window) and on the plasma membrane, budding of virions has not been seen. Release of virions from intact cells may be via the cellular secretory apparatus 


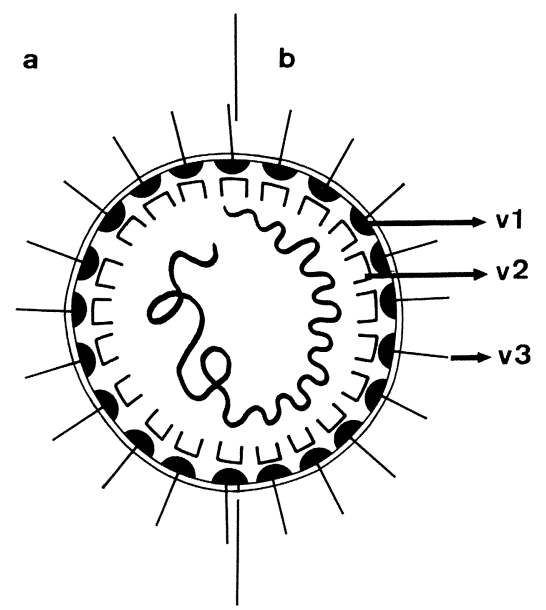

Fig. 8-18. Tentative model of the organization of a Flavivirus. The peplomers appear to consist of the V3 glycoprotein. A second, non-glycosylated envelope protein, V1, appears to lie beneath the lipid bilayer. The capsid protein, $V 2$, with the genomic RNA, forms a NC with cubic symmetry. (a) indicates that the RNA may be coiled within the capsid. Alternatively, the RNA may interact in a regular manner with the capsid protein V2 (b)

A major advance in the study of Flavivirus will be the development of molecular clones of the virus genes which will permit genetic mapping and analysis of virus protein synthesis, processing and transport. Monoclonal antibodies against the virus structural and non-structural proteins will also help to characterize the intracellular transport and processing of these proteins. Immunoelectron microscopy and cytochemical techniques such as those applied to the Alphaviruses will contribute to our understanding of the morphogenesis of Flaviviruses.

\section{Rubiviruses}

Rubella virus, which causes a mild exanthem in children and adults and can induce severe congenital malformations following intrauterine infection, is the only member of the Rubivirus genus. It is included in the Togaviridae family because of its structural similarities to other family members (Brinton, 1980). The virions are spherical particles 50 to $75 \mathrm{~nm}$ in diameter, containing $33 \mathrm{~nm}$ cores with cubic symmetry. A fuzzy layer of surface projections covers the virus envelope (Bardelletti et al., 1975; Murphy, 1980).

Rubella virus has a single-stranded RNA genome of MW $3-4 \times 10^{6}$. The genomic RNA is of positive polarity, since it is infectious. The virions contain at least 3 structural proteins: a NC protein, and two or three glycoproteins associated with the virus envelope (van Alstyne et al., 1981; Ho-Terry and Cohen, 1982; Okerblom et al., 1983).

Rubella virus matures by budding from intracellular membranes or, in some cells, from the plasma membrane (Murphy, 1980). It is unclear what factors 
determine the different budding sites of rubella virus. Like the Flaviviruses, no rubella virus NCs are observed free in the cytoplasm. Unlike the Flaviviruses, however, budding virions are readily observed in thin sections of infected cells.

\section{Pestiviruses}

The Pestiviruses, hog cholera virus and bovine diarrhea virus, show morphological and biochemical similarities to other togaviruses, although they are not arthropodborne (Murphy, 1980; Brinton, 1980). The virions are spherical particles 40 to $60 \mathrm{~nm}$ in diameter, with an indistinct layer of surface projections 6 to $8 \mathrm{~nm}$ long. The cores released from the virions appear to have cubic symmetry and are $25-30 \mathrm{~nm}$ in diameter (Horzinek, 1973 b).

The formation of Pestiviriuses is similar to the formation of Flaviviruses in that budding virons are hard to detect, no free NCs are observed in the cytoplasm and virions are released into the lumen of the RER or Golgi apparatus.

\section{Non-Arthropod-Borne Togaviruses}

Some non-arthropod-borne viruses including lactic dehydrogenase virus and equine arteritis virus have been included in the togavirus group because of morphological similarities (Brinton, 1980; Murphy, 1980; Horzinek, 1981). However, these viruses are structurally somewhat different from other togaviruses (Murphy, 1980) and they do not cross react serologically with any of them. It appears likely that they may form a separate genus within the family of Togaviridae. Additional studies on the molecular biology and assembly of the non-arthropod borne togaviruses will be required to aid in their classification.

The virions of equine arteritis virus are 50 to $70 \mathrm{~nm}$ in diameter and contain hollow cores of $35 \mathrm{~nm}$ diameter. The virions appear to form by budding into intracytoplasmic membranes (Murphy, 1980).

\section{Conclusion}

The Togaviridae family is a collection of several different types of small enveloped RNA viruses. It is clear that the mechanism of virus budding must be considered separately for each of the togavirus genera. Only the Alphaviruses have been studied sufficiently at the molecular level to permit construction of a detailed model of virus budding. Future molecular biological studies will elucidate the mechanisms for assembly release of the other togaviruses. 